\title{
A análise de redes sociais no mundo lusófono: contributos para o conhecimento de uma comunidade científica em desenvolvimento
}

\author{
Marta Varanda - ICS-UL (Portugal) \\ Raquel Rego - SOCIUS/ISEG-UTL (Portugal) \\ Breno Fontes - Universidade Federal de Pernambuco (Brasil) \\ Klaus Eichner - Universidade de Hamburgo (Alemanha)
}

\section{Resumo}

Neste artigo visamos caraterizar um conjunto de investigadores da área das ciências sociais que se distinguem pela utilização da análise de redes sociais (ars) como perspetiva teórico-metodológica e que circunscrevemos à partilha da língua portuguesa. A partir da caraterização sociográfica e da medição do sistema de interdependências entre estes investigadores (colaboração, aconselhamento e coautoria) pretendemos contribuir para a compreensão do desenvolvimento da ars no mundo lusófono, esboçando hipóteses explicativas dos fatores inibidores e estimulantes do seu desenvolvimento neste contexto linguístico.

Palavras chave: Análise de Redes Sociais - Brasil - Portugal - Lusofonia Ciências Sociais - Inovação Científica

\begin{abstract}
This article intends to characterize a group of social scientists we have distinguished by its use of social network analysis (SNA) as a theoretical and methodological perspective, and which we circumscribe to the lusophone's world. Through the characterization of their social profile and the measurement of these actors interdependencies (collaboration, advice and co-authorship), we wish to contribute to the explanation of the development of SNA in the lusophony. We elaborate hypothesis concerning the inhibitors and motivators of its development in this linguistic context.
\end{abstract}

Key words Social Network Analysis - Brazil - Portugal - Lusophone Community Social Sciences - Scientific innovation

\section{Introdução}

Contrariamente à perspetiva teórico-metodológica da análise de redes sociais (ARS), o conceito "redes" tem sido amplamente utilizado na literatura científica nas últimas décadas. A fluidez da interação nas sociedades contemporâneas (Castells, 1996), designadamente sob o auxílio das novas tecnologias de informação e comunicação, tornou o conceito de "redes" muito apelativo. Mas, para os analistas de redes sociais, o uso do conceito em sentido metafórico é muito limitado perante os métodos que a ARS tem desenvolvido e que permitem aumentar a capacidade explicativa das ciências sociais. Estes métodos consistem na medição e 
sistematização das regularidades sociais (padrões de relações). A sua ambição maior é a superação da dicotomia ator e estrutura, o que permite avanços importantes na teoria social. Como observam Marin e Wellman: "...network analysts are starting to develop methods to supplant explanations that too often relied upon descriptive techniques, verbal persuasiveness and esthetic appeal for acceptance ". (2010, p. 79).

A ARS começou a ser utilizada no âmbito das ciências sociais nos anos 30 do século XX com Moreno e Jennings nos EUA (Freeman, 2004). Nos anos 1970, a ARS sofre um forte impulso dado pelo grupo da Universidade de Harvard, liderado por Harrison White, e desde então tem vindo a crescer exponencialmente (Scott, 2000; Otte e Rousseau, 2002; Freeman, 2004; Knoke and Yang, 2008). Em 2004 Freeman afirmava que a "Network analysis is booming and the tendency for social scientists to ignore structure is diminishing..." (2004, p. 166).

O sucesso da ARS pode ser ilustrado pela sua progressiva institucionalização, em particular com a criação, em 1978, da associação International Network for Social Network Analysis (INSNA) e com a primeira edição do seu congresso anual, em 1981. Mas a sua institucionalização passa também pela existência de diversas revistas especializadas, designadamente a Social Networks, o Journal of Social Structure (online) e a revista REDES (online). Apesar da dominância anglosaxónica, a ARS expandiu-se também por outras regiões geográficas, como testemunham os balanços feitos por van Meter (2005), para os países francófonos, ou por Molina (2007), para os países hispânicos. Para o universo germânico, temos ainda o inventário feito por Ziegler (2010).

O mundo lusófono parece no entanto continuar pouco desperto para a ARS. Ao iniciarmos a nossa investigação, tínhamos a perceção de que a ARS no mundo lusófono teria um significativo atraso de desenvolvimento relativamente ao mundo anglo-saxónico, em particular. Efetivamente verificamos, por exemplo, que a primeira tese de doutoramento nesta área foi defendida por um português em 1993 no Canadá e a de um brasileiro no ano seguinte no Brasil; e que o primeiro artigo com aplicação de ARS é da autoria de um português e data de 1995, sendo o primeiro artigo de um autor brasileiro publicado em 1999. Os primeiros passos no uso da ARS no mundo científico lusófono foram dados, portanto, há menos de 20 anos.

Ao atraso no uso da ARS no mundo lusófono não será alheio o próprio atraso do desenvolvimento das ciências sociais nestes países. Em Portugal, em particular, os quase 50 anos de Estado Novo (1926-1974) limitaram o desenvolvimento de 
disciplinas como a sociologia ou a psicologia. Neste sentido, basta ter presente que a primeira licenciatura em sociologia surge em Lisboa só em 1978. O impacto do regime político autoritário sobre as ciências sociais não foi tão forte no Brasil por o seu desenvolvimento se ter iniciado antes da ditadura militar (1964-1985). Com efeito, o primeiro curso de sociologia surgiu na década de 1930 em São Paulo (Micelli, 1987; Silva, 2007). Mas a institucionalização das ciências sociais só se começa a consolidar a partir da década de 1960 quando surgem os primeiros cursos de pós-graduação. A formação de uma Rede Institucional para o financiamento de pesquisa e cursos de pós graduação (As Fundações Estaduais de Fomento à Pesquisa, e o Fortalecimento do CNPq e da CAPES $^{1}$ ) constituiu com efeito um elemento estratégico fundamental para a consolidação do sistema de pós graduação brasileiro.

Ao mesmo tempo que tínhamos evidência de algum atraso no uso da ARS no seio da comunidade científica lusófona, também tínhamos a noção de que a ARS tem vindo a crescer. O trabalho aqui apresentado pretende, pois, contribuir para o conhecimento desta inovação no mundo lusófono. Além disso, sabendo que a maior parte da investigação em torno das comunidades científicas não discute aspetos específicos das ciências sociais (UNESCO, 2010), a nossa investigação concorre também para colmatar a escassez e deficiência de dados disponíveis sobre os cientistas sociais e a sua atividade.

A nossa investigação não é a primeira a debruçar-se sobre o uso da ARS nas ciências sociais do mundo lusófono, mas os estudos existentes dedicaram-se a subdisciplinas das ciências sociais e/ou usaram fontes de dados secundários (e.g. Rossoni e Graeml, 2009; Graeml et al., 2010, Martins, 2011) em vez de questionarem diretamente os atores sociais, como é feito aqui. Esta abordagem, que é de resto também inédita a nível internacional, ${ }^{2}$ permitiu-nos conhecer pela primeira vez os atributos individuais e os padrões de interação dos analistas de redes sociais, assim como reconstituir de algum modo a história da ARS no mundo lusófono.

Este artigo está organizado em três partes. Num primeiro momento inscrevemos a nossa investigação no estado da arte sobre a introdução de uma inovação, a ARS, e

\footnotetext{
${ }^{1}$ Conselho Nacional de Desenvolvimento Científico e Fundação para o Aperfeiçoamento de Pessoal de Nível Superior, respetivamente.

2 Habitualmente os estudos sobre a introdução da ARS numa determinada comunidade científica recorrem a análise documental, designadamente das coautorias, em detrimento do questionamento direto dos atores.
} 
consequente expansão deste campo de conhecimento. Neste âmbito, a obra de Freeman (2004) constitui uma referência central.

Depois, apresentamos a metodologia que nos permitiu operacionalizar os nossos objetivos de investigação, descrevendo em seguida a comunidade científica lusófona que recenseámos. O critério usado para a delimitação do nosso universo foi o ter publicado pelo menos um artigo científico com ARS aplicada. A descrição da comunidade científica lusófona é feita quer do ponto de vista sociográfico, quer da trajetória profissional.

Finalmente, analisamos as relações de colaboração, aconselhamento e coautoria dos autores lusófonos. Com efeito, o padrão de relacionamento entre os atores que estiveram envolvidos na introdução e na difusão da ARS é fundamental para compreender o processo de emergência e expansão (Freeman, 2004). Importa com efeito não esquecer que a atividade científica é uma atividade social e nesta medida é constrangida pelas relações sociais (Moody, 2004). Ora, justamente ao relevarmos as relações sociais entre os atores desta comunidade, a metodologia mais adequada para o efeito é o uso da própria ARS. Na conclusão sumariamos as ideias centrais do artigo e esboçamos algumas hipóteses explicativas para os resultados encontrados.

\section{Enquadramento teórico - emergência e expansão do campo científico da ARS}

\section{As ciências sociais a nível global: uma estrutura centro-periferia}

A atividade científica cujo principal objetivo é a produção de conhecimento é cada vez mais uma atividade de abrangência internacional, que exige interação entre investigadores de múltiplas nacionalidades. Essa interação pode ter diferentes formas, desde a troca de informação informal entre investigadores, algumas levadas a cabo no seio de associações profissionais e de conferências por elas organizadas, à permuta de natureza formal, resultante da integração em equipas de investigação, conselhos editoriais, júris, etc.

Os países periféricos, como os países de língua oficial portuguesa, graças às novas tecnologias de informação e comunicação, aos investimentos públicos recentes na ciência, às viagens de avião a preços mais baixos, entre outros fatores, têm-se aproximado das comunidades científicas que dominam a produção em ciências sociais, inclusive no quadro da ARS. A mobilidade académica na periferia tem-se intensificado, a atestar por exemplo pela participação destes investigadores em 
encontros científicos de âmbito internacional e da assunção de cargos sociais nas associações profissionais internacionais.

De qualquer modo, a literatura tem demonstrado que a colaboração científica continua a ter uma estrutura dividida entre centro e periferia. Os países do centro são os que têm maior produtividade científica e correspondem aos países mais ricos e desenvolvidos, a saber da América do Norte e da Europa Ocidental. A intensidade da colaboração inter-regional entre os países do centro é testemunhada pelo número de publicações conjuntas e indexada na Web of Science, ou pelas citações que continuam a concentrar-se nas revistas científicas destes países. Apesar de alguns países periféricos terem já criado revistas no idioma inglês - lingua franca da comunidade científica internacional -, como a Brazilian Review of Social Science ou o The Portuguese Journal of Social Science, continuam a estar pouco integrados na produção científica à escala internacional. A sua posição resulta em parte do facto de as ciências sociais terem um objecto de estudo local, o que torna a internacionalização mais complexa (Gingras 2002; UNESCO, 2010).

Para quem está na periferia é sempre difícil romper com uma estrutura social que se baseia em mecanismos de "preferential attachment", segundo o qual "os ricos tornam-se mais ricos" (Wagner e Leyersdorff, 2006). Em boa parte a dificuldade em mudar esta tendência deve-se aos baixos custos da colaboração e maiores benefícios entre os países do centro do que entre os países da periferia, ou entre os do centro e os da periferia. Uma das ideias fundamentais do World Social Science Report, publicado pela UNESCO em 2010, é que a globalização e a internacionalização da investigação parecem ter favorecido essencialmente a América do Norte e a Europa Ocidental, as regiões que já eram dominantes no panorama científico (UNESCO, 2010).

No entanto, alguns autores apontam indícios de alteração deste estado de coisas. De acordo com Wagner e Leyersdorff (2006), as redes de colaboração internacional têm vindo a crescer a um ritmo muito significativo tornando-se mais densas ao longo do tempo. Identificou-se inclusivamente que o grau médio aumentou, ou seja, o número de passos entre atores é mais baixo do que dois e a tendência é para baixar. Dito de outro modo, qualquer investigador a trabalhar a nível global está teoricamente a dois apertos de mão dos outros.

\section{A construção do campo científico da ARS}


No início, um campo ${ }^{3}$ de investigação tem poucos membros que raramente se contatam entre si, mas, à medida que se produz investigação de interesse comum, novos membros vão surgindo e as relações vão-se intensificando. Entre os investigadores que entram no novo campo, alguns empenham-se fortemente, tornando-se muito ativos no ensino e investigação, passando a ser um ponto de referência para os outros atores do campo.

Os estudos que analisam o desenvolvimento da estrutura social informal, designadamente as redes de comunicação e de colaboração na comunidade científica internacional, demonstram que tanto as disciplinas como os países participam nessa comunidade em graus diferentes (Crane, 1972). Por exemplo, as disciplinas caracterizadas por um baixo grau de consenso - e.g. as ciências sociais e a sociologia em particular - tendem a ter tradições de investigação distintas e baixos níveis de cooperação internacional. Já as disciplinas caracterizadas por um alto nível de consenso - e.g. física e matemática - contêm áreas de investigação cujos membros são oriundos de países muito diferentes (Crane, 1972).

Esperar-se-ia assim que a ARS, nascida nas disciplinas das ciências sociais, fosse caracterizada pelos baixos níveis de consenso, geradores de conflitos habituais entre os pioneiros de um campo científico (Freeman, 2004). Na realidade durante os anos de emergência, dos anos 30 aos 70 do século $X X$, a fragmentação, a independência e a reduzida cooperação, ou mesmo fraco interconhecimento, eram características marcantes do campo da ARS. Os pioneiros e figuras de proa, que Freeman (2004) contabiliza em 21 ao todo, estavam em 5 países diferentes, a saber: França, Reino Unido, Holanda, Suécia e EUA; e eram provenientes de 7 disciplinas distintas: antropologia, psicologia social, matemática, biologia, sociologia, ciência política e psicologia experimental. No estudo de Freeman, os 21 pioneiros foram inquiridos e identificaram ao todo 68 figuras influentes e dessas 49 só foram mencionadas uma vez.

No entanto, a ARS não surge associada a conflitos, como nos dá conta Freeman (2004). Uma das principais razões para a inexistência, ou reduzida frequência de conflitos foi a base matemática da ARS que permite uma precisão à linguagem, que evita incompreensões sobre termos e conceitos. Outros fatores integradores e portanto inibidores de conflitos foram:

a) A produção de software de ARS que permitiu a estandardização da análise;

\footnotetext{
${ }^{3} \mathrm{O}$ conceito de campo é recuperado de Pierre Bourdieu para quem a sociedade se divide em múltiplos campos, ou seja, espaços de luta entre atores, cada um com a sua lógica própria mas também com regras comuns, conforme a sua obra traduzida para português O Poder Simbólico editada em 1989 pela Dífel.
} 
b) A criação de uma versão precursora da Internet para ligar as pessoas que faziam ARS;

c) A criação de uma associação que agregou os investigadores de ARS mundialmente;

d) A organização de conferências que juntaram grupos que estavam separados;

e) A mobilidade de estudantes e investigadores/docentes que criaram pontes entre os diversos grupos de analistas de redes;

f) A intervenção unificadora sobretudo da Universidade da California - Irvine.

De todos estes, o fator destacado por Freeman é a mobilidade de professores e estudantes (Freeman, 2004).

Se a questão da mobilidade se revela de grande importância para a superação de conflitos ela também o é para a difusão do conhecimento e vários autores têm-no reconhecido (e.g. Everett, 1995, Almeida e Kogut 1999, Allison e Scott, 1987). Com efeito, à medida que os investigadores (tal como outros trabalhadores) mudam de emprego, levam consigo o conhecimento, as competências e as relações de confiança construídas com os antigos colegas. É deste modo que Cantner e Graf (2006) demonstraram que as relações pessoais, que surgem através da mobilidade dos investigadores, são uma variável importante na explicação da formação de redes de cooperação.

\section{Adoção e difusão de uma inovação CIENTÍfICA: A ARS}

As ideias científicas ou tecnológicas são inovações ${ }^{4}$ que se difundem através da comunidade de cientistas. Os processos de difusão na comunidade científica são semelhantes aos de outras comunidades: antes de adotar uma inovação científica, cada investigador tem de ter conhecimento da inovação e decidir sobre a sua adoção. O conhecimento científico é transmitido tanto em livros, artigos de revistas científicas, apresentações em conferências, como através de fontes interpessoais de informação. De resto, tem-se vindo a argumentar que as relações interpessoais são especialmente importantes para a difusão do conhecimento e da informação, pois antes do trabalho publicado é discutido através de canais interpessoais dando

\footnotetext{
4 Segundo Rogers (1995), uma inovação é uma ideia, prática ou objeto percebido como novo pelo indivíduo ou outra unidade de adoção. Em termos do comportamento humano não é muito importante se a ideia é objetivamente usada pela primeira vez, ou se é uma invenção. O que interessa é a perceção da sua novidade pelo indivíduo/grupo que a irá usar. A inovação deixa de o ser depois de dada a sua difusão. A difusão funciona como um processo através do qual aqueles que adotaram a inovação vão persuadindo outros a fazê-lo também.
} 
origem a mecanismos de influência que afetam teorias e práticas de uma especialidade científica (Michaelson, 1993).

O peso da comunicação interpessoal versus publicações na transmissão de conhecimento em ciência tem de ser analisado em função da fase em que esta se encontra, isto é, se a ciência está em fase de "desenvolvimento" ou se em fase "normal". Usamos aqui o conceito de "ciência normal" (Kuhn, 1962, 1970) para designar um período da ciência em que a maioria dos investigadores segue um mesmo paradigma.

De acordo com Hummon e Carley (1993), ARS é uma especialidade em fase de "ciência normal" e não em fase de "desenvolvimento". O padrão de citações, o estilo dos artigos, a legitimação institucional, a existência de uma literatura comum, a presença de jovens que querem basear o seu trabalho nesta área, são todos aspetos que o indiciam. Nesta fase "normal", de acordo com Price (1986), os artigos em revistas e jornais científicos podem funcionar como uma forma de demarcar território e a difusão de inovações científicas depende sobretudo das relações sociais.

Já na fase de desenvolvimento da ciência, são os artigos de revistas que são importantes para recrutar novos cientistas para a área especializada. Nesta fase os inovadores estão na periferia e têm portanto relativamente poucas relações com outros. Os laços fortes não são os responsáveis por influenciar as decisões dos atores, designadamente de adoção de uma inovação.

Outros autores interessados pelas questões de desenvolvimento de uma área científica (e.g. Michaelson, 1993) chamam a atenção para a necessidade de termos em conta, não só a fase em que está a ciência, como a complexidade da inovação e a sua (in)compatibilidade com o conhecimento prévio ${ }^{5}$. Por exemplo, este autor comparou a difusão de duas inovações científicas dentro da área de ARS com níveis de complexidade e compatibilidade diferentes: estruturas posicionais e estruturas relacionais. A adoção de estruturas relacionais, que se considerou mais complexa e com maiores incompatibilidades face ao conhecimento preexistente, teve na sua base relações de amizade (i.e. os canais de influência são uma relação de laços fortes). Já relativamente à adoção de estruturas posicionais, uma inovação considerada menos complexa e mais compatível com o conhecimento prévio,

\footnotetext{
5 Para Rogers (1995), quanto mais complexa ou difícil de apreender a inovação, assim como quanto mais incompatível com teorias ou tecnologias já existentes, menos provável é que os atores as adotem, pelo que mais lentamente serão difundidas.
} 
verificou-se que numa fase inicial as relações interpessoais eram importantes mas que perderam valor mais tarde em favor das publicações.

Outros aspetos a ter em atenção nesta análise, pois podem favorecer ou inibir a adoção e difusão da inovação científica, têm a ver com a estrutura relacional do coletivo, no seu todo e ao nível dos seus subgrupos, e também com a existência de atores sociais com uma localização privilegiada para o efeito. No que concerne a estrutura relacional global tem-se considerado que a difusão é mais rápida quando a rede é centralizada, a estrutura é mais densa e existem laços fracos (Valente, 1995). Ao nível da localização dos atores sociais, sabe-se que os que têm o papel mais importante na adoção dessa inovação estão na periferia do sistema social e, em função disso, têm dificuldade em difundir a inovação só por si. Torna-se pois necessária a presença de atores com um papel mais central na rede, mas que sejam também capazes de fazer intermediação entre grupos (Menzel, 1960; Rogers 1995; Valente, 1995).

\section{Metodologia}

O objetivo principal da nossa investigação era conhecer a comunidade científica lusófona que utiliza ARS e compreender o processo que supúnhamos de lenta e tardia adoção da ARS. Propusemo-nos assim chegar até estes autores para os conhecer do ponto de vista sociográfico, compreender o seu percurso de aprendizagem, a sua prática de disseminação de uma nova área científica, assim como conhecer as eventuais interdependências que os caracterizam através da análise das suas redes de colaboração, aconselhamento e coautoria.

O trabalho empírico de recolha de dados dividiu-se em duas fases: (1) num primeiro momento fizemos pesquisa documental com base em diversas bases de dados acessíveis via Internet sendo o objetivo primeiro a identificação dos autores de publicações com ARS aplicada6 (terminada em Maio de 2010); (2) num segundo momento realizou-se um inquérito por questionário online dirigido aos autores identificados. A Internet constituiu, com efeito, uma ferramenta fundamental, não só para a primeira fase de recenseamento da comunidade, como também para chegar até ela e obter dados primários. A distância relativamente aos inquiridos e a falta de recursos com que este projeto foi desenvolvido foram obviadas através do recurso a esta tecnologia. O fato de os autores deste texto participarem desta comunidade de cientistas constituiu também uma fonte de informação complementar.

\footnotetext{
${ }^{6} \mathrm{E}$ não uma recolha exaustiva de todas as publicações dos autores
} 


\section{A base de dados de artigos ou a delimitação do nosso universo}

Para a recolha de informação documental os termos de busca utilizados em palavra-chave ou assunto foram "redes sociais" e/ou "social networks". Os autores considerados tinham de ser de nacionalidade lusófona ou radicados em países lusófonos e, embora essa informação não seja sempre evidente, a seleção teve em conta a origem do nome, a sua filiação institucional e/ou o tema do artigo.

Uma das primeiras conclusões desta recolha foi a inexistência de trabalhos sobre ARS da autoria de investigadores a trabalhar em instituições que não no Brasil e em Portugal. Ao falarmos em autores lusófonos e em comunidade lusófona estaremos, por conseguinte, a referir-nos estritamente ao Brasil e a Portugal.

A primeira fase de recolha de dados documentais foi aberta, isto é, procurámos artigos, livros, working papers, atas de encontros científicos e teses. Em consequência desta recolha, uma segunda conclusão que tirámos é que existem muitos documentos que incluem os conceitos "redes" ou "redes sociais" mas que não se referem à ARS, empregando sim o conceito de uma forma a que se tem chamado de metafórica (Wellman, 1988). Encontram-se ainda em número razoável publicações que mencionam a ARS mas sem a aplicar, que em geral são revisões teóricas da literatura de ARS. Em muito menor número estão os trabalhos em que é utilizada a literatura de ARS e aplicadas as medidas a dados originais.

Uma terceira conclusão que retirámos deste primeiro momento de recolha de dados, foi a existência de condições muito desiguais entre os dois países considerados no que diz respeito a organização dos sistemas de informação científica. As dificuldades operacionais foram várias. Deparámo-nos como seria de esperar com um grande volume de informação, mas também com uma variedade significativa de bases de dados. De facto, o Brasil tem estes dados centralizados e atualizados, enquanto que Portugal apresenta esta informação de forma dispersa e parcial.

Para o caso do Brasil há diversas bases de dados (de teses e dissertações, de grupos de investigação, de publicações científicas) que facilitam o acesso online. Neste caso, tomámos como ponto de partida o Banco de Teses da CAPES, o Diretório dos Grupos de Pesquisa do CNPQ, o Banco de Informações bibliográficas do SCIELO, para além de pesquisa no Google Académico. ${ }^{7}$

\footnotetext{
7 A busca a partir do banco de dados de Currículos do CNPq, Lattes, seria outra possibilidade, mas somente combinada com o de Grupos de Pesquisa, também do CNPq. Teríamos, a partir de informações de grupos de pesquisa, os nomes dos pesquisadores, para em seguida procedermos à busca Lattes. A partir daí, verificando suas publicações seguiríamos com a construção dos nomes que comporiam o
} 
Em Portugal não há nenhuma base que integre todas as publicações. Deste modo, as buscas tiveram de ser feitas em diferentes bases de dados correndo-se o risco maior de não sermos exaustivos. De referir também que muitas publicações não têm a versão integral online, nem estão inseridas nas bases de dados internacionais. Nestes casos, encontrada apenas a referência, procurámos a versão em papel. A base de dados primeiramente explorada para Portugal foi a COLCAT. Trata-se de uma base de dados de bibliotecas universitárias. Como base de dados de teses utilizámos a do Gabinete de Planeamento, Estratégia, Avaliação e Relações Internacionais do Ministério da Ciência, Tecnologia e Ensino Superior. Para além destas, recorremos a outras bases internacionais para a identificação de artigos por autores lusófonos, a saber a Revista REDES, a Social Networks e publicações na Web redes, no Google académico, na SCIELO, na B-on (via Colcat), e na ISI Web of knowledge. Em todo o caso, as fontes de pesquisa são relativamente incompletas e apenas nos levaram indiretamente ao nosso objeto empírico de investigação. As limitações das bases de dados levaram-nos a fazer buscas repetidas de forma a termos uma maior segurança sobre a qualidade dos dados recolhidos.

Finalmente, construída a base de dados de artigos podemos identificar claramente os autores lusófonos que já usaram ARS. Esta base de dados inclui também informação sobre os trabalhos ou publicações (autores, título, etc.), a classificação do conteúdo da $\mathrm{ARS}^{8}$, área disciplinar, filiação institucional e localização geográfica. Constituindo sem dúvida material para futuras explorações e não sendo a nossa fonte de dados privilegiada neste artigo, ela permitiu-nos alargar o nosso conhecimento servindo pontualmente neste artigo.

\title{
O inquérito por questionário online aos analistas de redes lusófonos
}

\begin{abstract}
nosso universo de pesquisa. Talvez fosse um procedimento mais completo, mas, diante dos custos envolvidos (há um número relativamente grande de pesquisadores que participam dos mais de cem grupos de pesquisa indexados com a expressão "redes sociais"), decidimos pela busca a partir da bibliografia sobre redes, construindo o nosso universo com aqueles pesquisadores que publicaram e tiveram seus artigos indexados nestes bancos de dados bibliográficos acima referidos. Cremos, também, que os resultados obtidos com dois procedimentos não seriam muito diferentes.

${ }^{8}$ A profusão de trabalhos com a utilização do conceito "redes" obrigou a uma análise dos artigos visando a diferenciação entre os vários usos do conceito de redes. Começamos por diferenciar entre dois grandes grupos: 1) ARS "metáfora" - não aplica medidas de ARS, não utiliza bibliografia clássica de redes sociais, conceito "redes" como fluidez, flexibilidade; 2) ARS "não metáfora": neste caso dividimos entre ARS aplicada vs. ARS não aplicada. Relativamente ao que considerámos ARS não aplicada encontrámos três tipos de situações. A primeira consiste na realização de uma análise empírica onde se transformam as relações em atributos. Este é o caso de estudos que incluem inquéritos com questões relacionais, como por exemplo se tem amigos, vizinhos etc., e fazem contagens desses contactos transformando estas medidas relacionais em atributos de ego (não constroem portanto uma matriz quadrada); b) análise empírica com enfoque importante de redes de relações mas que se restringe à visualização (por ex. realização de sociograma à mão); c) texto teórico em que os conceitos e a bibliografia utilizada são muito baseados na literatura de ARS. A ARS aplicada consiste numa ARS com análise empírica, onde se aplicam as medidas de redes, quase sempre com uso de software.
\end{abstract}


Depois desta fase de recolha e análise documental, retiveram-se os artigos publicados em revistas científicas que utilizassem corpo teórico e aplicassem medidas de medidas de ARS. Excluíram-se portanto atas de conferências, working papers, capítulos de livros e outros. Esta opção foi feita considerando que um artigo corresponde, de um modo geral, a um trabalho amadurecido e tendo em conta as limitações de recursos de que dispúnhamos.

Ao todo identificaram-se no Brasil 62 e em Portugal 22 autores e coautores de artigos científicos com aplicação de ARS, ou seja, ao todo 84 autores de língua portuguesa. Estes autores e coautores de artigos com aplicações de ARS foram então alvo de uma nova pesquisa para se obterem os seus emails e enviarmos o inquérito por questionário online. Esta constituiu a principal técnica de recolha de dados primários em que baseamos o trabalho apresentado neste artigo.

A opção pelo inquérito online deve-se à facilidade de aplicação, baixo custo de execução, facilidade e rapidez de resposta. O programa do inquérito foi feito de raíz e o facto de dispormos da base de sondagem permitiu-nos controlar eventuais duplicações de respostas, assim como proceder a uma insistência selectiva. Pudemos com efeito inquirir indivíduos dos dois países geograficamente afastados sempre com o mesmo procedimento. Esta modalidade de inquérito ajusta-se bem ao público-alvo, pois, trata-se de uma população letrada (sobretudo investigadores e professores universitários) que à partida utiliza as novas tecnologias de informação e comunicação. Esta escolha acabou por ser a mais eficiente, até porque nos permitiu recolher os dados em tempo real.

O inquérito online, concebido e gerido por um elemento da equipa de investigação, foi enviado em Novembro de 2010. Num esforço de obter o maior número possível de inquéritos fizemos 4 lembretes. Os inquéritos foram assim recebidos até Maio de 2011.

A taxa de resposta ficou nos 55\%: 51,6\% (32 inquiridos) no Brasil e 59\% (13 inquiridos) em Portugal, ou seja, a nossa amostra é composta por um total de 45 inquiridos. Tendo em conta as médias praticadas nesta modalidade de inquérito, podemos dizer que este resultado é satisfatório. A relativa fraca adesão dos inquiridos poderá, a nosso ver, passar pelas habituais razões de não resposta, como excesso de solicitações, mas também por outras mais específicas, como por exemplo o caso de coautores que não responderam por não terem participação na componente ARS dos artigos coletivos. 
Em estudos de ARS que pretendem fazer a análise da rede global, uma não reposta é sempre um problema operacional. No nosso caso, apesar de um número significativo de autores e coautores não terem respondido, sabemos que só 3 autores no Brasil e 1 em Portugal, que tinham sido nomeados por outros como conselheiros, não responderam ao inquérito. Portanto, só estes 4 casos são considerados uma limitação importante do estudo. De notar que, no que diz respeito a colaboração, existem ainda 7 outras não respostas de autores que foram nomeados como colaboradores e que constavam da nossa base ${ }^{9}$.

A literatura de ARS aborda muito insuficientemente a questão de como lidar com não respostas. Esta realidade não deixa de ser estranha visto que as não respostas são prováveis dada a complexidade de um inquérito de redes, e que a análise e mapeamento da estrutura da rede é especialmente sensível a dados missing. A existência de não respostas pode dificultar a compreensão das estruturas e subestruturas relacionais e portanto do fenómeno social em causa. Uma das formas pragmáticas de lidar com este problema tem sido restringir a atenção para o subconjunto de indivíduos acerca do qual temos informação completa, o que implica uma redefinição da "fronteira" estabelecida previamente (Kossinets, 2006). Neste estudo optámos por essa redefinição da fronteira da amostra, ficando assim uma matriz quadrada de $45 \times 45$. Esta matriz foi analisada com o uso do software UCINET V versão 6.347 e do Netdraw 2.111 para a representação gráfica.

O inquérito por questionário dividiu-se em três grandes tipos de questões:

a) Dados sociográficos: filiação institucional, área disciplinar, percurso profissional (ano, instituição, etc.), qualificações académicas (grau, instituição, ano), dando sempre enfoque especial ao uso e formação em ARS;

b) Dados sociométricos: relações redes de colaboração, aconselhamento (com qualificação da relação - formal e informal - e meio de comunicação utilizado), coautorias e orientações;

c) Estímulo inicial e iniciativas de difusão da ARS: indicação dos meios que suscitaram o interesse pela ARS - pessoa, publicação, cursos, etc. -; envolvimento na disseminação da ARS através da organização de cursos, conferências, etc.;

\section{Resultados}

\section{A tímida presença da comunidade científica lusófona no campo da ARS}

\footnotetext{
${ }^{9} \mathrm{O}$ que poderá ser uma evidência de que tenha havido colaboração com colegas sem competências em ARS.
} 
Como enunciámos atrás, numa primeira exploração do nosso objeto, procurámos detetar a presença de analistas de redes sociais lusófonos na comunidade internacional de redes sociais. Neste sentido, adotámos várias estratégias, a saber: procurámos a sua filiação em associações científicas de ARS, a sua presença em mailing lists de divulgação de informação sobre o tema e, usando o indicador mais comum na literatura, reunimos os artigos da sua autoria em revistas com avaliação por pares ("peer review"). Deste modo, em Janeiro de 2012 havia 14 brasileiros e 6 portugueses registados na INSNA de um total de 1549 membros. Na Web REDES, a lista de discussão associada à Revista REDES, cuja subscrição é gratuita, estavam presentes 72 brasileiros e 13 portugueses num total de 500 registos. Identificámos ainda 11 artigos em língua portuguesa em 18 volumes com 151 artigos ao todo na Revista REDES, a única revista científica especializada que publica em português. Nenhum artigo foi encontrado na Connections, no JOSS (Journal of Social Structure) nem na Social Networks, as revistas especializadas em ARS de língua inglesa. Se ao invés de considerarmos só as revistas anglo-saxónicas especializadas em ARS, incluirmos outras revistas indexadas internacionalmente, por exemplo no ISI Web of Knowledge, verificamos também a fraca presença dos analistas de redes: 4 artigos publicados em revistas não lusófonas e 8 em revistas lusófonas (dados recolhidos em maio de 2011).

Estas informações revelam o que poderíamos chamar de tímida presença dos analistas de redes lusófonos na comunidade internacional de analistas de redes sociais. E se a pouca visibilidade dos analistas de redes não será muito diferente do que sucede com a comunidade de cientistas sociais de um modo geral, não deixa de constituir uma motivação para procurarmos compreender o processo de desenvolvimento desta perspetiva teórico-metodológica no seio da lusofonia.

No levantamento inicial de artigos com aplicações de ARS apercebemo-nos que o grande crescimento se dá a partir de meados de 2000. Embora este levantamento não tenha sido exaustivo é indicador de uma tendência (ver gráfico 1.). 


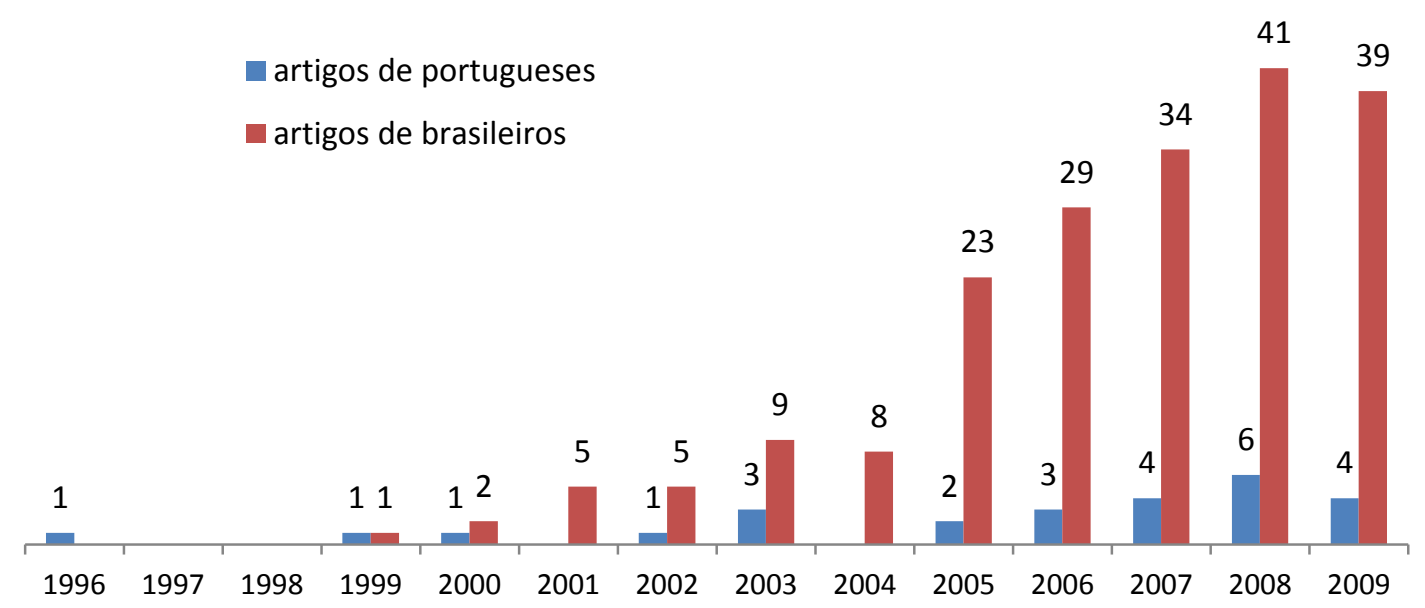

Gráfico 1: Número de artigos com ARS aplicada por nacionalidade dos autores (1996-2009). Fonte: Recenseamento de artigos com ARS aplicada (2010).

\section{Caracterização da comunidade científica: os analistas de redes sociais lusófonos}

Centramo-nos agora na análise dos investigadores que no Brasil e em Portugal publicaram artigos em revistas com peer review com ARS aplicada e que responderam ao nosso inquérito online, a saber uma amostra de 45 indivíduos.

Traços sociográficos e trajetórias profissionais

Como era esperado, há uma desigualdade importante na representação das nacionalidades tendo em conta as diferentes dimensões das comunidades científicas em causa, a brasileira e a portuguesa. Assim, do total da amostra, 31 indivíduos têm afiliação institucional no Brasil (ainda que destes, 3 não tenham nacionalidade brasileira) e 14 têm afiliação institucional em Portugal.

A dispersão geográfica e institucional dos inquiridos é importante. Embora haja cidades onde se reúne um aglomerado relativamente grande de inquiridos, tal como São Paulo (11) e Lisboa (7), os restantes investigadores estão distribuídos em 6 cidades brasileiras diferentes e em Portugal em 5 cidades diferentes e duas ilhas. Em termos institucionais verificámos, assim, que os 45 autores estão inseridos em 39 instituições diferentes, o que configura claramente uma grande dispersão.

As idades dos inquiridos oscilam entre os 28 e os 65 anos sendo a média global de 46 anos (46,6 anos para o Brasil e 43 anos para Portugal). A maioria dos inquiridos 
é do sexo masculino $(64,4 \%)$, sendo a proporção de homens superior no Brasil $(67,7 \%)$ em relação a Portugal $(57,1 \%)$.

A maior parte dos inquiridos desempenha funções de docência $(59,1 \%)$ e um quarto são investigadores $(25,0 \%)$. Os autores brasileiros acentuam esta distribuição ( $71,0 \%$ contra $22,6 \%$ ) pois no Brasil não existe praticamente a carreira de investigador mas só de professor /investigador, enquanto em Portugal o peso é igual para estas duas funções. No mesmo sentido, verificamos que as instituições a que pertencem os inquiridos são sobretudo de natureza académica, pois $70,8 \%$ dos brasileiros trabalham na universidade e $25,0 \%$ num centro de investigação; sendo a distribuição igual para estas organizações por parte dos portugueses. Estes valores seriam de esperar sobretudo para o caso do Brasil onde a Universidade é o lugar de investigação por excelência.

A área disciplinar de trabalho mais representada na amostra é a gestão $(31,1 \%)$ seguida da sociologia $(20,0 \%)$ e da ciência política $(11,1 \%)^{10}$. Mas esta distribuição é muito desigual quando comparamos os dois países. Como se pode ver na tabela seguinte, no Brasil há sobretudo autores de artigos com ARS do domínio da gestão enquanto em Portugal os autores são em primeiro lugar sociólogos.

\begin{tabular}{l|lc}
\hline Áreas Disciplinares & Brasil & Portugal \\
\hline Gestão & 44,0 & 25,0 \\
Sociologia & 20,0 & 33,3 \\
Ciência Política & 20,0 & - \\
& $(n=31)$ & $(n=14)$ \\
\hline
\end{tabular}

Tabela 1. Principais áreas disciplinares de trabalho dos inquiridos por país (\%). Fonte: Inquérito aos analistas de redes lusófonos (2011)

Relativamente à formação académica é de notar que quase todos os inquiridos têm pelo menos o mestrado. Com efeito, $42(93,3 \%)$ dos 45 inquiridos têm este grau académico e 36 o doutoramento ( $80 \%$ ). Todos os brasileiros inquiridos detêm o grau de mestre e 83,8\% são doutorados. Quanto aos portugueses, 11 em 14

10 As outras áreas presentes na nossa amostra são a antropologia, psicologia, economia, geografia, história, ciências da informação, para além de uma categoria residual de outras. 
$(78,6 \%)$ têm o mestrado e $10(71,4 \%)$ têm o doutoramento. Trata-se, por conseguinte, de uma comunidade bastante qualificada.

Apenas uma pequena parte dos inquiridos com doutoramento obteve este diploma numa universidade fora do seu país $(17,8 \%)$. E um pouco mais de metade dos doutorados $(52,8 \%)$ usou ARS na sua tese (enquanto que no mestrado só $30 \%$ aplicou ARS). Dos brasileiros doutorados, 4 em $26(15,4 \%)$ fizeram a sua tese numa universidade estrangeira e nenhum aplicou então ARS. Dos restantes 22 doutorados, realizados em Universidades brasileiras, metade usou ARS nas suas teses. De entre os 10 portugueses doutorados, 4 (40\%) defenderam também a sua tese numa universidade estrangeira, 3 dos quais usaram ARS, sendo que dos restantes 6 doutorados em Portugal, 5 usaram ARS. Observa-se assim que só cerca de metade da comunidade de analistas de redes lusófona usa a ARS já na sua formação académica e que os portugueses parecem obter na formação no estrangeiro uma influência importante para o uso da ARS. A questão da internacionalização, isto é, da passagem por instituições de outros países, é fundamental para uma área científica em desenvolvimento sobretudo quando estão em causa investigadores da periferia. A partir da combinação de diversas variáveis, construímos um índice de internacionalização da comunidade de analistas de redes lusófonos. Este índice é composto por: (1) formação em universidade estrangeira (pelo menos um dos graus), (2) estadia em instituição estrangeira (pelo menos uma vez), (3) publicação com autor de instituição estrangeira (quer como autor quer como coautor) e (4) eventual vínculo a instituição estrangeira (atualmente). De notar que consideramos para este efeito também como estrangeiro o Brasil em relação aos autores portugueses e Portugal para os autores brasileiros.

Deste modo, o nosso índice de internacionalização permite-nos concluir que a internacionalização da comunidade lusófona é muito baixa, pois a média da amostra é de 0,82 numa escala que vai de 0 , nenhuma ligação ao estrangeiro, a 4 grande ligação ao estrangeiro, quando assinala alguma ligação em todas as quatro variáveis consideradas, acima identificadas. A média para a comunidade brasileira é de 0,74 e para a portuguesa é de 1 . Estes dados refletem o fato de que, apesar de os brasileiros terem realizado seus estudos de doutoramento predominantemente no seu país, há no seu percurso profissional posterior, intensificação de cooperação académica internacional, aproximando-os dos seus colegas portugueses.

A Tabela seguinte discrimina os valores para as variáveis que compõem o índice de internacionalização consideradas por país e no global da amostra, mostrando claramente que as parcerias na publicação são a forma de colaboração menos 
utilizada e dando conta também da ligeira maior internacionalização dos inquiridos portugueses face aos brasileiros.

\begin{tabular}{l|lll}
\hline Indicadores de Internacionalização & Brasil & Portugal & Total \\
\hline Estadia em Instituição Estrangeira & 25,8 & 35,7 & 28,9 \\
$\begin{array}{l}\text { Formação em Instituição estrangeira } \\
\begin{array}{l}\text { Vínculo Institucional em Instituição } \\
\text { estrangeira }\end{array}\end{array}$ & 125,8 & 35,7 & 28,9 \\
$\begin{array}{l}\text { Publicação com autores de Instituição } \\
\text { estrangeira }\end{array}$ & 9,7 & 14,3 & 13,3 \\
& $(n=31)$ & $(n=14)$ & $(n=45)$ \\
\hline
\end{tabular}

Tabela 2. Índice de Internacionalização (\%). Fonte: Inquérito aos analistas de redes lusófonos (2011)

No nosso inquérito interessámo-nos ainda pela mobilidade institucional dos inquiridos procurando saber a sua atual inserção institucional, os vínculos institucionais anteriores as organizações académicas de formação e as instituições onde eventualmente os inquiridos realizaram estadias de curta duração relacionadas com o uso da ARS.

O primeiro resultado que gostaríamos de salientar é que nenhum dos nossos inquiridos do Brasil passou por alguma instituição portuguesa e nenhum inquirido de Portugal passou por uma instituição brasileira. Este dado evidencia de facto uma falta de coesão desta comunidade científica lusófona que se poderia esperar facilitada pela comunhão da língua apesar do oceano que a separa.

Já a mobilidade institucional em cada país parece ser importante, se relevarmos que $42,2 \%$ dos inquiridos estão atualmente integrados numa organização onde nunca tinham estado antes, quer em termos laborais quer formativos, e que $67 \%$ teve pelo menos um vínculo institucional com outra instituição que não a sua actual. É também relevante o facto de que $42,2 \%$ da nossa amostra tenha passado por uma instituição estrangeira, em formação doutoral, ou em estágios de cooperação internacional

Considerando em particular a estadia por curtos períodos noutra instituição, um pouco mais de metade da nossa amostra $(53,3 \%)$ assinala ter feito por exemplo um curso, ou apresentado um seminário noutra instituição académica que não aquela onde se encontra atualmente a exercer funções. Destes investigadores, metade (12 em 24) fizeram-no em organizações estrangeiras da Europa, EUA ou América latina. 
Se atentarmos depois na formação académica, verificamos que da grande maioria $(73,3 \%)$ que estudou numa instituição distinta daquela onde se encontra no momento do inquérito, mais de $1 / 3(36,4 \%)$ obteve pelo menos um diploma numa universidade estrangeira, de novo nas regiões geográficas indicadas no parágrafo anterior.

A comunidade lusófona que publicou artigos com ARS é pois uma comunidade "móvel" e portanto potenciadora de difusão de conhecimento e de criação de relações interinstitucionais.

Do despertar para a ARS às iniciativas para a sua disseminação

De forma a sabermos o que despertou o interesse pela ARS colocámos diretamente essa questão. Mais de metade da nossa amostra $(54,8 \%)$ referiu como primeira fonte de informação para despertar o interesse pela ARS uma pessoa, podendo esta ser um colega, aluno, ou professor. De notar que destes, $24 \%$ referem pelo menos um investigador estrangeiro.

Em segundo lugar $(38,1 \%)$ surge a leitura de um livro ou artigo e em terceiro lugar, com um número reduzido de respostas $(7,2 \%)$, identificam-se outros tipos de fontes, como um curso, um website, etc. Cerca de $33 \%$ respondem ter tido influência apenas de publicações, evidenciando uma tendência para o autodidatismo, o que se explicará pela fraca institucionalização e ausência de oferta significativa de cursos de formação no seu contexto de trabalho.

\begin{tabular}{l|ll}
\hline Fonte de interesse & Brasil & Portugal \\
\hline Uma pessoa (colega, aluno ou professor) & 58,6 & 46,2 \\
Leitura de um texto (artigo, libro) & 37,9 & 38,5 \\
Outros tipos (curso, website, etc) & 3,4 & 15,4 \\
& $(\mathrm{n}=29)$ & $(\mathrm{n}=13)$ \\
\hline
\end{tabular}

Tabela 3. Primeira fonte de interesse pela ARS (\%). Fonte: Inquérito aos analistas de redes sociais lusófonos (2011)

De notar que dos inquiridos que referem alguma leitura como responsável pelo despertar do interesse pela ARS, sobressai a obra de John Scott (2000), Social Network Analysis - A Handbook, como a mais popular:4 referências como primeira fonte de influência e várias outras depois. Este resultado deve-se possivelmente ao facto de ser uma obra didática e onde a componente matemática não é pronunciada. 
As iniciativas de disseminação da ARS são ainda recentes, escassas e pouco sistemáticas, o que contribui para que afirmemos que estamos perante uma fase de desenvolvimento da ARS na comunidade científica lusófona. A oferta de formação em ARS tem sido uma das atividades desenvolvidas pelos autores de ARS. Uma parte importante dos nossos inquiridos $(42,2 \%)$ terá estado envolvido na organização de um curso com conteúdos relativos à ARS. As primeiras ofertas de formação conhecidas, em geral no formato de curso intensivo, foram realizadas já nos anos 2000, tanto em Portugal como no Brasil. A componente ARS está integrada em cursos de métodos em algumas universidades brasileiras e portuguesas $^{11}$, mas a oferta regular de cursos/disciplinas em Análise de Redes Sociais é ainda muito rara e recente. Não podemos pois dizer que haja um campo disciplinar consolidado nas Universidades Brasileira e Portuguesa. O mesmo número de analistas de redes lusófonos (42,2\%) tem orientado teses com uso de ARS. E o primeiro encontro científico sobre o tema, do qual temos conhecimento, terá sido realizado em Portugal em 2003, tendo já varias edições depois. De notar contudo que um pequeno grupo de indivíduos da nossa amostra $(22,2 \%)$ tem estado envolvido na promoção destes eventos. Não se conhecem no entanto

Finalmente, não podendo deixar de revelar uma fraca institucionalização da ARS, importa acrescentar que não são conhecidas associações científicas ou profissionais no campo da ARS nestes países.

\section{Redes sociais da comunidade de analistas de redes sociais lusófonos}

As análises realizadas neste artigo incidem sobre três tipos de relações, a saber: colaboração, aconselhamento e coautoria no seio da comunidade de analistas de redes lusófonos. Estes três tipos de relações têm na sua base formas de interação diferentes, com expetativas e exigências diversas de ambas as partes. Todas elas estão, contudo, interligadas pois fazem parte da atividade relacional dos investigadores com os seus pares no dia-a-dia. Por exemplo a relação que exige maior compromisso entre as partes é a coautoria e é, não raras vezes, o culminar de uma boa relação de colaboração.

As questões sociométricas colocadas foram:

A - Por favor enumere as pessoas com quem já colaborou ou colabora em projetos de investigação que recorram à ARS;

\footnotetext{
${ }^{11}$ As informações disponíveis via internet são muito parcelares e não nos informam sobre a atualidade destes cursos, por isso optámos por não incluir uma listagem dos mesmos.
} 
B - Indique por favor todas as pessoas com quem tira dúvidas e/ou se aconselha sobre problemas de investigação relacionados com ARS;

C- Caso tenha publicado artigos em coautoria utilizando ARS em revistas com "peer review" por favor indique o(s) nome(s) e instituição(ões) do(s) seu(s) (co-) autor(es ).

Pareceu-nos ainda interessante examinar o carácter multifuncional das relações entre estes investigadores, pois pode-nos dar uma melhor ideia do padrão de interdependências global entre eles. Por exemplo, a rede multifuncional, composta pela junção das três relações, permite-nos detetar outros padrões de interação, que em função da multiplexidade da interação espelham as relações mais fortes.

$\mathrm{Na}$ interpretação dos resultados da análise de redes faremos apelo a outros dados recolhidos via inquérito que não necessariamente os sociométricos e a informação recolhida a partir do que os autores deste artigo - membros desta comunidade científica - observam em suas atividades profissionais.

\section{A rede global dos analistas de redes lusófonos}

\section{Correlação QAP e homofilia geográfica}

No sentido de compreender em que medida estas três relações se correlacionam efetivamente foi utilizado o procedimento QAP (quadratic assignment procedure). Nesta comunidade científica lusófona que é o nosso caso de estudo existe uma alta correlação $(0,777)$ entre colaboração e coautoria. A relação de colaboração está também muito correlacionada com a de aconselhamento (0.656), ou seja, os investigadores de ARS aconselham-se muito junto dos seus colaboradores. Este dado é importante tendo presente a baixa sofisticação metodológica da maioria dos artigos que nos conduziram à identificação dos investigadores de língua portuguesa que usam ARS. Com efeito, podemos dizer que, à partida, o facto de se aconselharem maioritariamente entre si indicia um baixo valor acrescentado na aprendizagem mútua.

Esta tendência será aqui possivelmente ampliada devido à maior dificuldade de acesso a outros conselheiros, por exemplo internacionais, e ao provável desconhecimento de potenciais conselheiros da mesma nacionalidade, que poderão estar distantes geograficamente. 


\begin{tabular}{l|ccc}
\hline Colaboração & 3,93 & 3,44 & 0,48 \\
Aconselhamento & 1,76 & 1,2 & 0,5 \\
\hline
\end{tabular}

Tabela 4. Valores médios de conselheiros e colaboradores. Fonte: Inquérito aos analistas de redes lusófonos (2011). $\mathrm{N}=45$.

Os dados da Tabela em cima corroboram o que acabou de ser dito, isto é, a contagem de todos os conselheiros nomeados pelos 45 investigadores, e que podem não constar da nossa base de dados, revela que os analistas de redes têm ao todo em média 1,76 conselheiros (1,2 lusófonos e 0,5 não lusófonos). Quando nos cingimos aos conselheiros que são ao mesmo tempo inquiridos da nossa base, essa média é de $0.82^{12}$, o que nos parece ser um valor baixo tendo presente a complexidade que pode implicar uma ARS.

Verificamos também que uma percentagem importante dos conselheiros são igualmente amigos ou grandes amigos dos aconselhados (quase 69\%). Esta tendência de aconselhamento entre os próximos e semelhantes é amplamente descrita na literatura organizacional e sobre comunidades (e.g. Monge, Contractor, 2003; Borgatti , Cross, 2003; Brass, 1995 , Festinger et al. 1950). O que está na base desta correlação é, portanto, por um lado, a fácil acessibilidade (pedir conselho a quem colabora connosco) e a proximidade emocional. Isto faz com que a rede de aconselhamento seja geralmente restrita.

O papel da condicionante geográfica ${ }^{13}$ nos padrões de interação pode ser analisado com base no índice E- $\mathrm{I}^{14}$ (Krackahrdt e Stern, 1988). O primeiro resultado a notar é, de novo, a praticamente total ausência de relações de colaboração entre os investigadores brasileiros e os portugueses, bem expresso no valor $-0.933^{15}$ do índice E-I. Esta conclusão vai ao encontro da análise feita antes sobre a mobilidade institucional entre os dois países.

Se em vez do país tivermos em atenção a cidade ou Estado onde habitam os inquiridos, obtemos um índice de E-I de -0.400 na relação de colaboração (e de -

12 Este valor é inferior à média global de nomeações de conselheiros, pois, como dissemos, tivemos não respostas ao inquérito e vários dos conselheiros citados não tinham publicações com aplicações de ARS (por nós identificados) ou eram ou de áreas disciplinares que não as ciências sociais.

13 Considerámos 13 localizações geográficas: 7 cidades portuguesas (Lisboa, Porto, Coimbra , Aveiro, Évora, Funchal , S. Miguel) e 6 Estados brasileiros (São Paulo, Paraná, Bahia, Minas Gerais, Santa Catarina e Pernambuco) .

${ }^{14} \mathrm{O}$ índice E-I permite calcular o nível de homofilia (ou heterofilia) através da medição do número de laços para o interior vs exterior do grupo definido, neste caso a localização geográfica (Hanneman e Riddle, 2005)

15 Os valores de homofilia variam de -1-a 1, sendo --1 é o valor máximo de homofilia (Hanneman e Riddle, 2005) 
0.467 na relação de aconselhamento). Sendo bastante inferior ao Índice E-I relativo ao país, revela a importância da cidade/Estado onde se exerce funções no condicionamento das interações. Na relação de coautoria este peso aumenta para 0.579 .

Estes resultados indicam que existe entre os analistas de redes lusófonos uma tendência para a relação com os que trabalham na mesma cidade, mas que não é forte ao ponto de excluir relações mais distantes. Esta tendência para a homofilia, i.e. a tendência dos atores sociais se relacionarem mais com os do mesmo grupo, neste caso os fisicamente próximos e semelhantes (e.g. Festinger et al. 1950, Mcpherson, et al , 2001; Rossoni e Graeml, 2009), apesar das tecnologias de comunicação e informação (e.g. Wellman e Haythornthwaite 2002), vai ao encontro do que tem sido discutido e demonstrado pela literatura sobre o campo da ARS.

\begin{tabular}{l|lll}
\hline & Colaboração & Aconselhamento & Coautoria \\
\hline Total de laços & 60 & 60 & 38 \\
E-I & -24 & -28 & -22 \\
E-I índex & $-0,400$ & $-0,467$ & $-0,567$ \\
Significância & $<0,05$ & $<0,05$ & $<0,05$ \\
\hline
\end{tabular}

Tabela 5. Relações de Colaboração, Aconselhamento e Coautoria segundo total de laços. Fonte: Inquérito aos analistas de redes lusófonos (2011). $n=45$

Finalmente, a correlação entre a relação de coautoria e aconselhamento é um pouco mais baixa do que a correlação entre colaboração e coautoria mas ainda assim alta - 0.577. Neste estudo, a relação de aconselhamento parece significar, mais do que a habitual relação entre professor/aluno, indicadora de assimetrias, uma divisão de trabalho, na colaboração em projetos e em coautorias, entre os que têm maior e menor competência em tratamento de dados por exemplo.

\section{Visualização e medidas de coesão}

Quando visualizamos os sociogramas das redes dos investigadores lusófonos (Gráficos 2 e 3), a primeira imagem evidencia a sua fraca atividade, ou seja, a pouca intensidade de interação entre estes investigadores. 

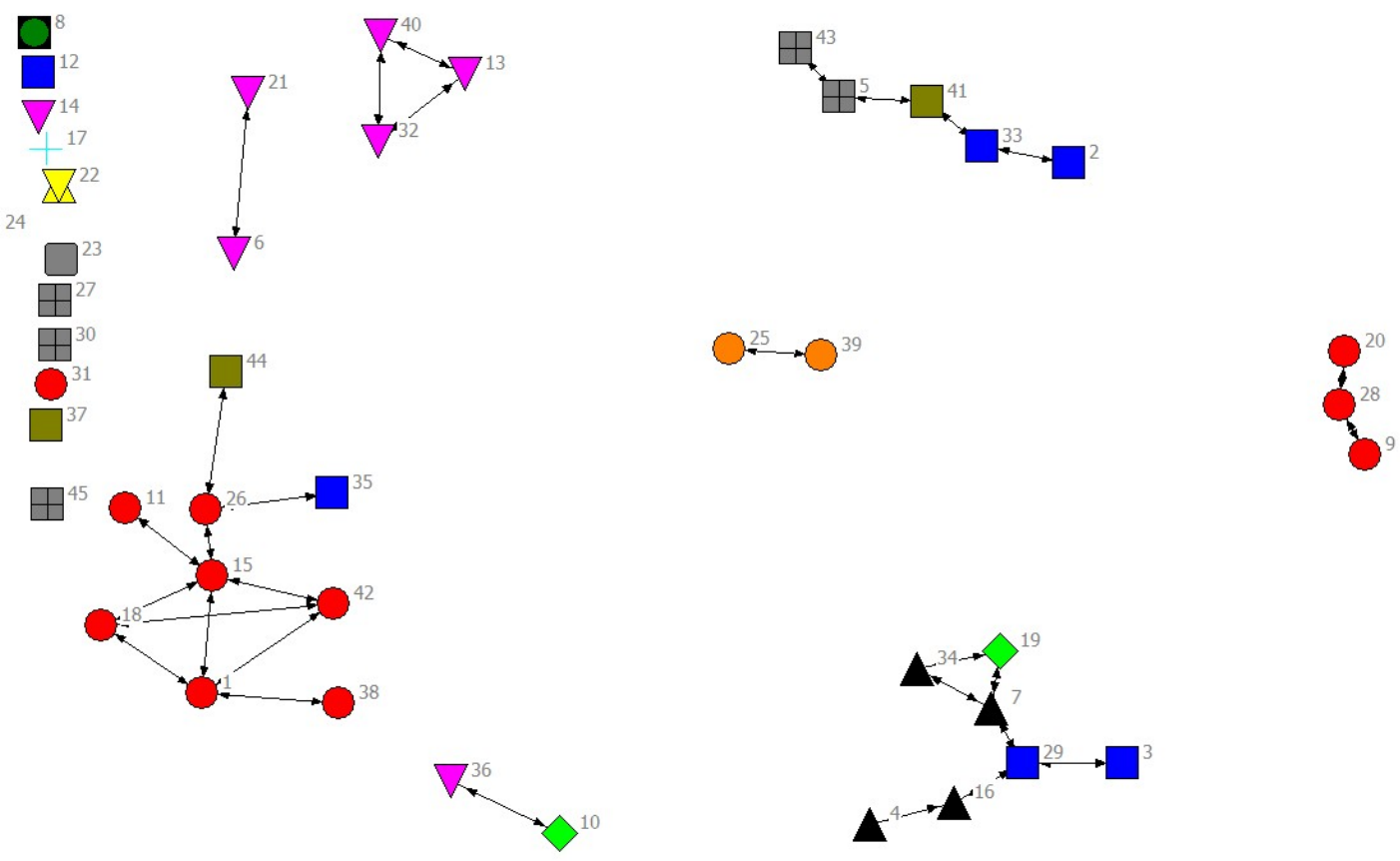

Gráfico 2. Rede de colaboração dos analistas de redes lusófonos

Legenda: 1) São Paulo: vermelho/bola; 2) Paraná: azul forte/quadrado; 3) Bahia: Preto/triângulo; 4) Minas Gerais: cinzento/quadrado com cruz; 5) Lisboa: cor-de-rosa/triângulo invertido; 6) Santa Catarina: circulo verde-escuro dentro de quadrado); 7) Pernambuco: verde-claro/diamante; 8) Funchal (Madeira): cruz azul claro; 9)Évora: Amarelo; 10) Coimbra Cinzento/quadrado; 11) S. Miguel (Açores): sem forma; 12) Aveiro: cor de laranja/bola; 13) Rio de Janeiro : verde caqui/quadrado.

FONTE: Inquérito aos analistas de redes lusófonos (2011). N=45.

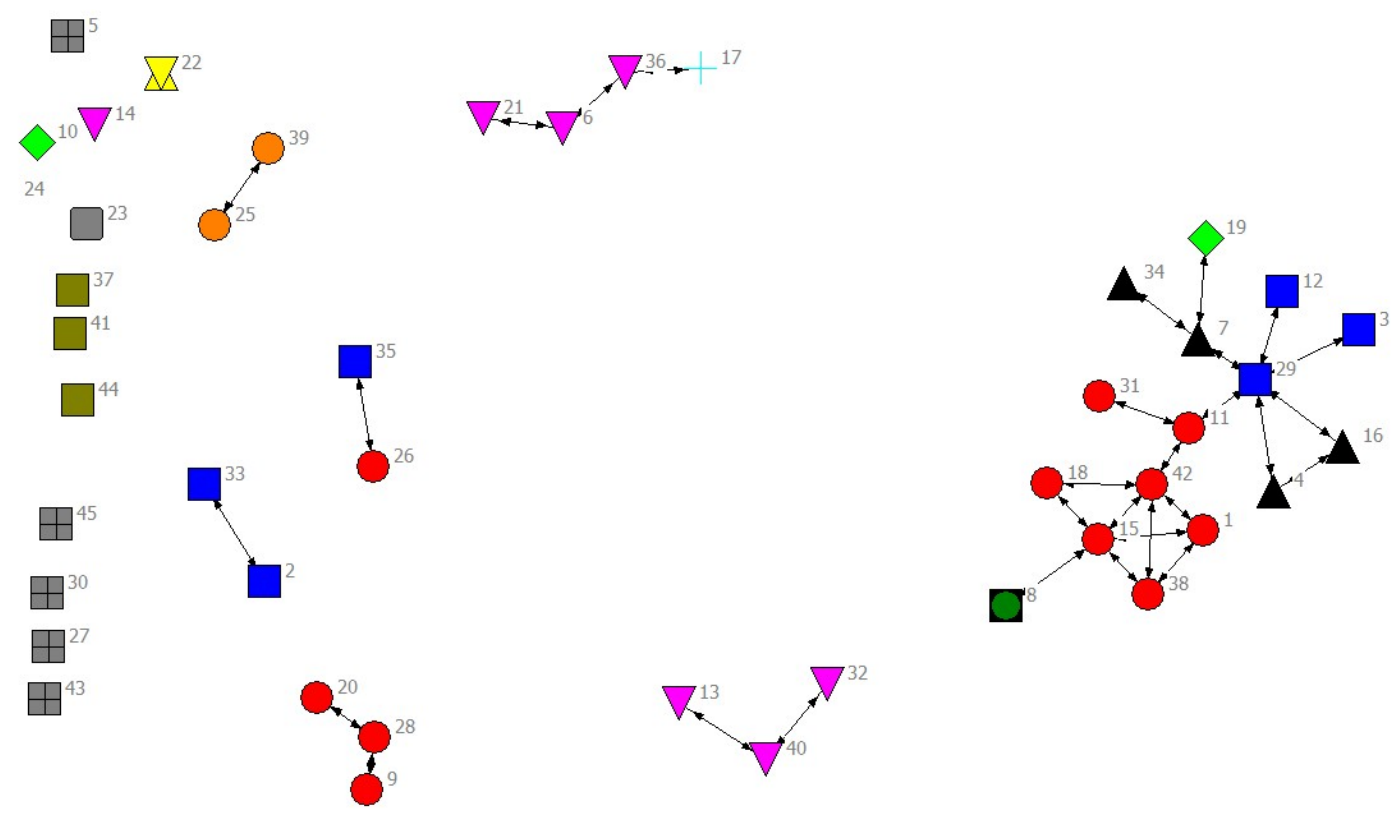


Gráfico 3. Rede de aconselhamento dos analistas de redes lusófonos

Legenda: 1) São Paulo: vermelho/bola; 2) Paraná: azul forte/quadrado; 3) Bahia: Preto/triângulo; 4) Minas Gerais: cinzento/quadrado com cruz; 5) Lisboa: cor-de-rosa/triângulo invertido; 6) Santa Catarina: circulo verde-escuro dentro de quadrado); 7) Pernambuco: verde-claro/diamante; 8) Funchal (Madeira): cruz azul claro; 9)Évora: Amarelo; 10) Coimbra Cinzento/quadrado; 11) S. Miguel (Açores): sem forma; 12) Aveiro: cor de laranja/bola; 13) Rio de Janeiro : verde caqui/quadrado.

FONTE: Inquérito aos analistas de redes lusófonos (2011). N=45. 

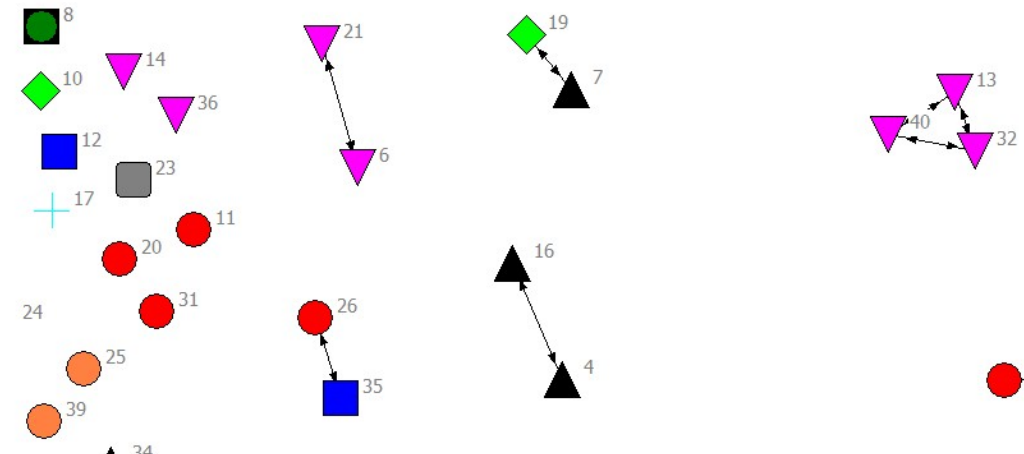

$\mathbf{\Delta}^{3}$
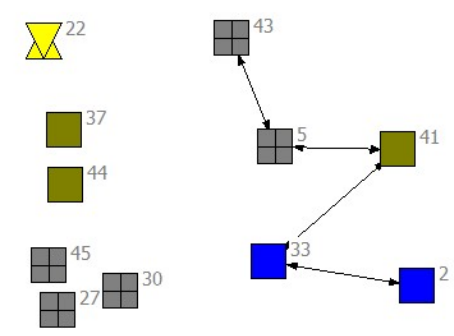

Gráfico 4. Rede de coautoria dos analistas de redes lusófonos

Legenda: 1) São Paulo: vermelho/bola; 2) Paraná: azul forte/quadrado; 3) Bahia: Preto/triângulo; 4) Minas Gerais: cinzento/quadrado com cruz; 5) Lisboa: cor-de-rosa/triângulo invertido; 6) Santa

Catarina: circulo verde-escuro dentro de quadrado); 7) Pernambuco: verde-claro/diamante; 8) Funchal (Madeira): cruz azul claro; 9)Évora: Amarelo; 10) Coimbra Cinzento/quadrado; 11) S. Miguel (Açores): sem forma; 12) Aveiro: cor de laranja/bola; 13) Rio de Janeiro: verde caqui/quadrado.

FONTE: Inquérito aos analistas de redes lusófonos (2011)

$$
n=45
$$



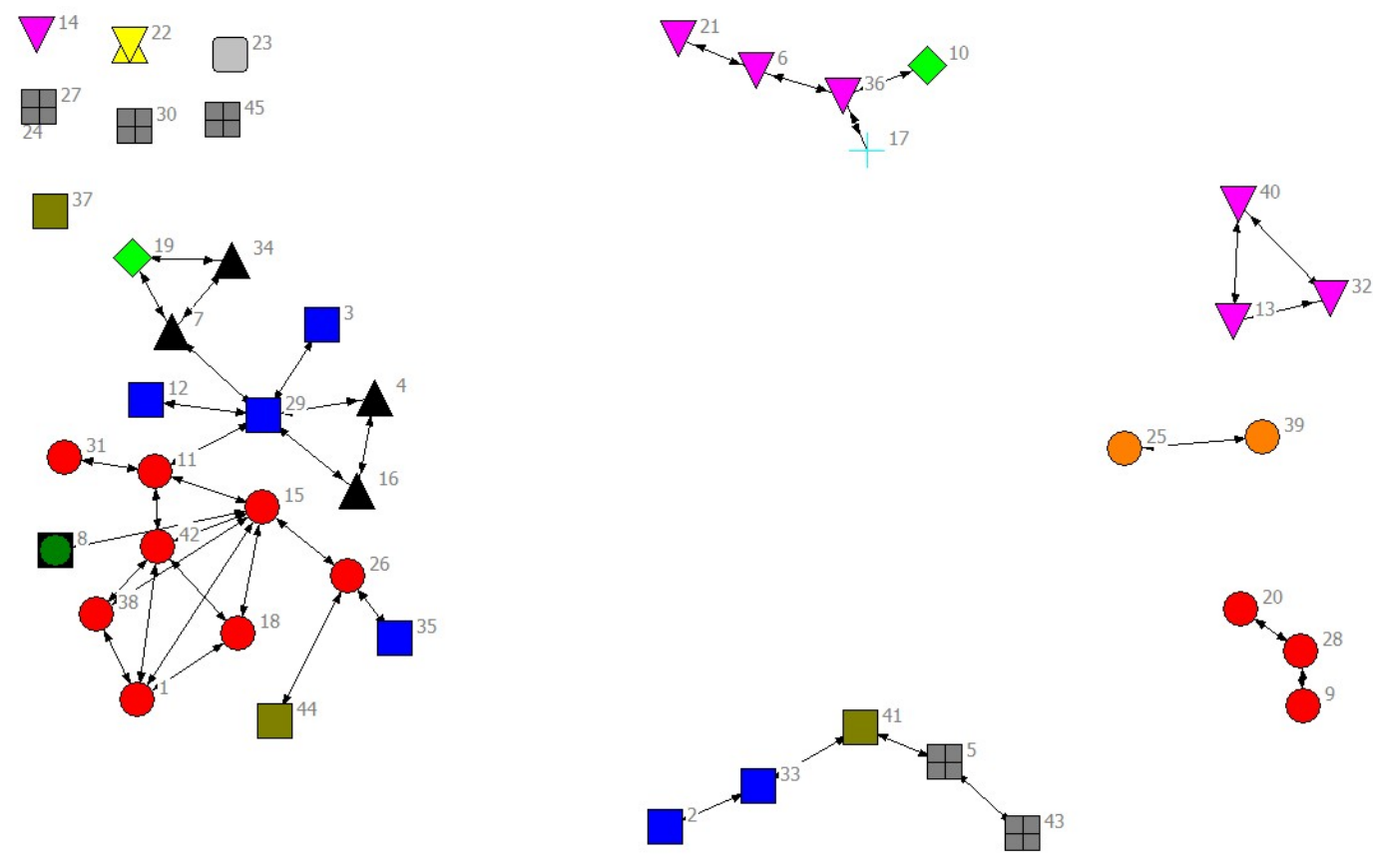

Gráfico 5. Rede multiplexa dos analistas de redes lusófonos

Legenda: 1) São Paulo: vermelho/bola; 2) Paraná: azul forte/quadrado; 3) Bahia: Preto/triângulo; 4) Minas Gerais: cinzento/quadrado com cruz; 5) Lisboa: cor-de-rosa/triângulo invertido; 6) Santa Catarina: circulo verde-escuro dentro de quadrado); 7) Pernambuco: verde-claro/diamante; 8) Funchal (Madeira): cruz azul claro;9)Évora: Amarelo; 10) Coimbra Cinzento/quadrado; 11) S. Miguel (Açores): sem forma; 12) Aveiro: cor de laranja/bola; 13)Rio de Janeiro : verde caqui/quadrado.

FONTE: Inquérito aos analistas de redes lusófonos (2011). $\mathrm{N}=45$. 
De forma a aprofundar a informação obtida através dos sociogramas apresentamos e analisamos de seguida algumas medidas de caracterização da rede global.

\begin{tabular}{l|llllll}
\hline & Densidade & $\begin{array}{l}\text { Grau } \\
\text { médio }\end{array}$ & $\begin{array}{l}\text { No } \\
\text { isolados }\end{array}$ & Reciprocidade & Centralização \\
\hline Colaboração & $3,03 \%$ & 1,33 & 12 & 0,533 & $8,52 \%$ \\
Aconselhamento & $3,03 \%$ & 1,33 & 13 & 0,200 & $10,85 \%$ \\
Coautoria & $1,92 \%$ & 0,84 & 20 & 0,526 & $5,017 \%$ \\
Rede multiplexa & $7,98 \%$ & 3,51 & 8 & 0,600 & $6,58 \%$ \\
\hline
\end{tabular}

Tabela 6. Medidas de caracterização da rede global

NOTA: para esta análise as matrizes foram simetrizadas exceto na medida de reciprocidade. FONTE: Inquérito aos analistas de redes lusófonos (2011) $\mathrm{n}=45$

Os valores apresentados na Tabela 6 revelam a baixa densidade e baixo grau médio destas redes, que traduzem de novo a sua fraca atividade. Os valores do grau médio indicam que os investigadores têm igual, mas muito reduzido acesso a colegas com quem se aconselhar e colaborar e que esse acesso baixa quando nos referimos à coautoria. Ainda com base no quadro referido, ficamos a saber que existe um grau de reciprocidade considerável na relação de colaboração: -0,533. No entanto, no aconselhamento, e como seria de esperar, a reciprocidade é mais baixa, sendo neste caso bastante mais baixa: 0.200 . Este baixo nível de reciprocidade no aconselhamento pode indicar assimetrias no grau de conhecimento sobre ARS, ou seja diferentes níveis de autoridade informal, que no entanto não se traduzem em distanciamento, pois, como vimos, as relações de aconselhamento estão altamente correlacionadas com as de colaboração (e coautoria), e os conselheiros são na sua maioria considerados amigos/grandes amigos. De notar ainda a muito baixa centralização ${ }^{16}$ de todas estas redes. 0 facto de estas serem redes muito esparsas e muito descentralizadas torna mais difícil a coordenação de esforços e as iniciativas conjuntas por esta comunidade de

${ }^{16}$ Uma rede centralizada é uma rede que concentra num pequeno número de membros grande parte da atividade de interação da rede global; pelo contrário, numa rede descentralizada a interação está dispersa por entre os membros da rede (e.g. Wasserman e Faust, 1984). 
investigadores. Parece, em suma, clara o estado prematuro do desenvolvimento da comunidade científica lusófona no que respeita a ARS.

Os subgrupos da REDE: Componentes

Através da análise de componentes é também facilmente percetível a enorme fragmentação que caracteriza estas redes. Para a interpretação da composição dos componentes é importante ter em mente a localização geográfica e a tendência para a homofilia geográfica dos atores, mas também os efeitos da mobilidade de alguns investigadores que motivaram as relações entre investigadores em áreas geográficas distantes.

\begin{tabular}{l|llll}
\hline & $\begin{array}{l}N^{0} \\
\text { componentes }\end{array}$ & $\begin{array}{l}N^{0} \\
\text { componentes } \\
\text { com ou 3 ou } \\
\text { mais atores }\end{array}$ & $N^{0}$ isolados & Fragmentação \\
\hline Colaboração & 20 & 5 & 12 & 0,923 \\
Aconselhamento & 20 & 4 & 13 & 0,864 \\
Coautoria & 29 & 3 & 20 & 0,971 \\
Rede Multiplexa & 14 & 5 & 8 & 0,800 \\
\hline
\end{tabular}

Tabela 7. Caracterização dos componentes. NOTA: para esta análise as matrizes foram simetrizadas. Fonte: Inquérito aos analistas de redes lusófonos (2011). $n=45$

Nas três relações examinadas, existem certos componentes cuja composição é recorrente. De notar que em nenhuma das relações analisadas existe um componente, de dimensão 3 ou superior que reúna investigadores brasileiros e portugueses.

Na relação de colaboração identifica-se uma componente formada essencialmente por investigadores do Estado de São Paulo ligados à Universidade de São Paulo (USP_SP), o grupo mais alargado dentro de uma só universidade. Este núcleo da USP tem no entanto ligação com outros investigadores de outra zona geográfica, que se deve em particular a um ator que identificámos como tendo muita mobilidade geográfica, da UFABC_SP. Chamamos a atenção para uma outra componente composta por 3 investigadores de São Paulo ligados à Pontifícia Universidade Católica (PUC_SP) e que não têm qualquer relação com os analistas de redes da USP.

Um terceiro componente é formado à volta de uma investigadora do Rio de Janeiro (RJ), cuja mobilidade estendeu geograficamente a sua rede de colaboração e orientações a investigadores de Minas Gerais (Belo Horizonte - BH) e de Londrina (Paraná) (LOND_PAR). 
Um outro componente tem uma presença forte de investigadores de Salvador (Bahia) em que um deles tem ligações com um investigador de Curitiba (Paraná) CUR_PAR) que abre a componente para outras zonas geográficas. A última componente com mínimo 3 atores é composta por portugueses ligados a um centro de investigação situado no ISCTE-Instituto Universitário de Lisboa, em Lisboa (ISCTE-IUL).

No que respeita a relação de aconselhamento, importa notar o surgimento de um novo componente composta por investigadores portugueses de diferentes instituições, também centrado em Lisboa, e o facto de que o componente de maior dimensão juntar atores de USP_SP com BAHIA_PAR através de um ator indiretamente ligado à USP_SP.

$\mathrm{Na}$ relação de coautoria verifica-se um aumento da fragmentação da redes, já esperada por a relação de coautoria ser a que exige maior nível de compromisso e investimento dos atores.

A matriz multiplexa revela uma fragmentação mais reduzida da rede, só com 14 componentes, mas a composição das componentes altera-se pouco. Como antes, a componente geográfica está presente, mas existe abertura de interação, frequentemente despoletada pela mobilidade dos investigadores, em situações de doutoramento, ou estadias curtas noutras universidades.

Em suma, através da análise de componentes podem-se detetar os grupos de investigadores mais implicados na ARS. A sua localização geográfica, bem como o efeito da mobilidade de alguns dos seus membros são os fatores que nos pareceram mais explicativos desta divisão em grupos: por um lado temos um grande grupo de USP_SP, por outro as ligações entre investigadores da Bahia e do Paraná, que se ligam aos primeiros quando se trata de aconselhamento, temos também um componente com diversidade geográfica (RJ - LOND_PAR - BH) e um grupo coeso em Lisboa.

\section{Os subgrupos da rede: cliques e 2 clans}

O tipo de interação de que falamos aqui - a colaboração, aconselhamento e coautoria - que é fundamental para o percurso de aprendizagem e desenvolvimento do trabalho dos investigadores, pode revestir-se de grande complexidade, não só pelos conteúdos da discussão, mas também pelas diferenças de estatuto entre investigadores, pelas diferentes visões dos problemas em discussão, etc. Em resposta os investigadores, tal como outro tipo de profissionais (e.g. Lazega, 2001; Piña Stranger, 2011) procuram e fomentam a criação de 
subgrupos coesos que são espaços de solidariedade onde o processo de aprendizagem se torna mais fácil e recompensador, tanto profissional como emocionalmente. Neste estudo procuramos detetar estes subgrupos coesos através das medidas de cliques e n-clans, pois sendo "espaços" fundamentais à aprendizagem científica é interessante conhecer quem entre os analistas de redes tem (ou não) acesso a eles.

\begin{tabular}{|c|c|c|c|}
\hline & $\begin{array}{l}\text { No } \\
\text { cliques }\end{array}$ & $\begin{array}{l}\text { No 2- } \\
\text { clans }\end{array}$ & $\begin{array}{lr}\text { Clusters } & \text { de } \\
\text { Sobreposição dos } \\
\text { N-clans }\end{array}$ \\
\hline Colaboração & 3 & 11 & $\begin{array}{l}\text { 1) USP_SP; } \\
\text { 2)RJ-BH; } \\
\text { 3)ISCTE_LX; } \\
\text { 4)PAR-Bahia; } \\
\text { 5) PUC_SP } \\
\text { (nível de corte: 0,196) }\end{array}$ \\
\hline Aconselhamento & 3 & 8 & $\begin{array}{l}\text { 1) USP_SP; } \\
\text { 2)PAR-Bahia; } \\
\text { 3)ISCTE_LX; } \\
\text { 4)LX-FUnchal; } \\
\text { 5) PUC_SP } \\
\text { (nível de corte: 0,525) }\end{array}$ \\
\hline Coautoria & 3 & 6 & $\begin{array}{l}\text { 1) USP_SP; } \\
\text { 2)RJ-BH; } \\
\text { 3)ISCTE_LX; } \\
\text { (nível de corte : 0,600) }\end{array}$ \\
\hline Rede multiplexa & 6 & 12 & $\begin{array}{l}\text { 1) USP_SP; } \\
\text { 2)PAR-Bahia; } \\
\text { 3)RJ-BH } \\
\text { 4)ISCTE_LX; } \\
\text { 5)LX-FUnchal; } \\
\text { 6) PUC_SP } \\
\text { (nível de corte:0,248) }\end{array}$ \\
\hline
\end{tabular}

Tabela 8. Caracterização das cliques e 2-clans

FONTE: Inquérito aos analistas de redes lusófonos (2011)

NOTA: para esta análise as matrizes foram simetrizadas; em anexo os quadros com os clusters hierárquicos da sobreposição dos n-clans $\mathrm{n}=45$

$\mathrm{Na}$ rede de colaboração identificaram-se 3 cliques, uma que inclui 4 investigadores ligados à USP, outra que inclui 3 investigadores de Lisboa (ISCTEIUL), e uma outra com 3 atores ligados a um investigador da Bahia (um dos atores da clique não está na Bahia mas foi seu doutorando).

No que respeita a matriz de aconselhamento identificaram-se 3 cliques, duas que juntam investigadores da USP e uma que junta investigadores de Curitiba (Paraná) e Bahia. De notar a inexistência de cliques de aconselhamento formadas por investigadores portugueses e também de investigadores brasileiros de outras 
regiões, que não USP_SP, PAR e Bahia. Portanto, se analisarmos a relação de aconselhamento, observamos que a maior parte dos investigadores não tem acesso a aconselhamento em contextos de grupos coesos, que muito facilitam a transferência de conhecimento e a aprendizagem mútua. Na relação de coautoria encontram-se 3 cliques duas compostas por investigadores das USP_SP e uma por investigadores do ISCTE-IUL.

O reduzido número e pequena dimensão das cliques ${ }^{17}$ confirmam os baixos níveis de coesão nestas redes e a dispersão dos investigadores. O passo natural é então reduzir a exigência de coesão das cliques e aplicar a medida 2 - clan ${ }^{18}$. Focaremos a nossa interpretação nos clusters da matriz de sobreposição dos n-clans, pois de acordo com Borgatti e Everett (1998) é mais útil e mais explicativo analisar os clusters da matriz de sobreposição do que analisar cada n-clan de per si, devido à frequente sobreposição dos atores.

Os subgrupos obtidos através da medida 2-clan reforçam a informação obtida através das cliques e componentes. Com efeito, demonstra-se que esta rede é constituída por um no considerável de pequenos grupos (e.g. $11 \mathrm{n}$-clans na rede de colaboração e 12 na rede multiplexa) mas que são de pequena dimensão ( 3 e 4 nodos na maioria ${ }^{19}$ ), o que revela a reduzida coesão ao nível global da rede. Mas, por outro lado, estes subgrupos, e em particular as cliques, demonstram a existência de pequenos grupos que funcionam aparentemente com uma lógica de equipa, com uma solidez que indicia relações de solidariedade importantes para o trabalho científico. As diferentes medidas aplicadas de subgrupos, componentes, 2clans e cliques demonstram ainda a importância da distância geográfica tanto para a colaboração como para o aconselhamento. Esta, distância geográfica é encurtada quando existe mobilidade institucional de algum investigador e/ou relações de orientação inter-universitárias.

\section{Análise de centralidade}

As medidas de centralidade são medidas que nos indicam a atividade, importância e prestígio dos atores, relacionado com o seu acesso diferenciado aos recursos. Teremos aqui em atenção as medidas de centralidade de grau e intermediação (Freeman, 1979).

\footnotetext{
17 Todas as cliques têm dimensão 3 à exceção de uma clique na rede de colaboração de dimensão 4 e duas, igualmente de dimensão 4 , na rede multiplexa.

18 Utilizamos esta medida em vez da 2-clique pois em certas circunstâncias esta pode ser insuficientemente coesa (Wasserman e Faust, 1994)

${ }^{19}$ Embora na rede de colaboração haja um n-clan de dimensão 6, na de aconselhamento um n-clan de dimensão 8 , e na rede multiplexa um n-clan de dimensão 8 e outro de dimensão 7.
} 


\begin{tabular}{l|llll}
\hline $\begin{array}{l}\text { Ranking } \\
\text { Grau }\end{array}$ & Colaboração & Conselho & Coautoria & Multiplexa \\
\hline 1 & USP-SP & CUR_PAR & USP_SP & USP-SP \\
& & & & \\
2 & USP_SP & USP_SP & USP_SP & USP_SP \\
3 & Vários ${ }^{20}$ & USP_SP & USP_SP & USP_SP e \\
& & & & CUR_PAR \\
\hline
\end{tabular}

Tabela 9. Ranking das medidas de centralidade de grau FONTE: Inquérito aos analistas de redes lusófonos (2011) $\mathrm{n}=45$

Verificamos que os valores de grau são muito baixos tanto na colaboração como no aconselhamento. Os valores de colaboração mais altos caracterizam os investigadores da USP_SP e são o resultado de uma forte colaboração intra-grupo. Estes resultados são verdadeiros também para a relação de coautoria. Já no topo do grau de aconselhamento temos também, para além dos investigadores da USP_SP um investigador de Curitiba.

Esta é mais uma evidência da fraca atividade desta rede intralusófona: não há figuras líderes que se destaquem na ARS lusófona, há sim um fechamento dos atores com maior grau de centralidade nos seus pequenos grupos

\begin{tabular}{l|llll}
\hline Ranking & Colaboração & Conselho & Coautoria & Multiplexa \\
intermediação & & & & \\
\hline 1 & USP_SP & CUR_PAR & RJ & CUR_PAR \\
2 & UFABC_SP & USP_SP & Lond_PAR & USP_SP \\
3 & CUR_PAR & USP_SP & USP_SP & USP_SP \\
\hline
\end{tabular}

Tabela 10. Ranking das medidas de centralidade de intermediação FONTE: Inquérito aos analistas de redes lusófonos (2011) $\mathrm{n}=45$

${ }^{20}$ USP_SP + BAHIA + CUR_PAR + SA_SP 
Por seu lado, a centralidade de intermediação dá-nos informação sobre os atores que têm um papel relevante na ligação entre outros atores desse sistema social. No nosso caso, as rede estão dividida em muitos e pequenos componentes e por isso a intermediação é muito reduzida.

Na relação de colaboração têm maior protagonismo dois atores do Estado de São Paulo, um da USP_SP e outro da UFABC_SP, que é um dos atores com maior mobilidade geográfica. Na relação de aconselhamento no topo da intermediação temos atores de CUR_PAR, da USP_SP e da BAHIA. É de notar que um destes atores é ainda estudante de doutoramento. A centralidade de intermediação de coautoria tem no topo uma investigadora do RJ, e ex-orientandos de outras instituições - Londrina_PAR e MG - um dos exemplos de continuação da colaboração entre orientador e orientandos.

$\mathrm{Na}$ rede multiplexa, temos no topo da centralidade de grau investigadores da USP_SP, o que é semelhante ao que tínhamos visto nas matrizes desagregadas. No topo da centralidade de intermediação temos atores que já estavam no topo do aconselhamento, sendo só um deles um investigador próximo do grupo da USP_SP, os vários outros são, como se espera em medidas de intermediação, investigadores que não estão integrados em grupos, ou que são de alguma forma marginais no seu grupo.

Note-se que o grupo da USP_SP está muito mais presente no topo da centralidade de grau do que da intermediação: só um dos investigadores está no topo da centralidade de intermediação, o que indicia mais uma vez a forte coesão intragrupo existente na USP_SP.

\section{Conclusões}

Uma das primeiras impressões de que partimos para a nossa investigação foi a de que a ARS era uma área científica ainda pouco desenvolvida na comunidade científica lusófona ${ }^{21}$. Esta impressão foi resultado de uma perceção "a olho nu" do baixo número de publicações de artigos em revistas com revisão "peer review" e da sua fraca institucionalização. Com efeito, a presença da ARS nos curricula do ensino superior em Portugal e no Brasil é aparentemente baixa, e as associações científicas e profissionais são desconhecidas ou inexistentes. Se esta impressão foi o nosso ponto de partida, o nosso inquérito aos autores veio comprová-la.

${ }^{21}$ Contrariamente, tal como já referimos, ao uso do conceito "redes" e "redes sociais" que é utilizado abundantemente em artigos, livros, teses, designação de grupos de pesquisa... 
Numa apreciação geral do sistema de interação entre os analistas de redes lusófonos pode-se dizer que é um sistema pouco dinâmico e muito fragmentado o que revela um campo científico pouco institucionalizado, que vive ainda das raras interações informais entre os seus investigadores (provavelmente em muitos casos por desconhecimento uns dos outros).

Esta fragmentação era também característica da comunidade internacional pioneira da ARS, conforme vimos na revisão da literatura. Uma das consequências que daqui resultam é o fraco acesso ao conhecimento que existe na própria rede e a incapacidade de utilizar os recursos disponíveis. Mas se a comunidade de analistas de redes lusófona é composta por pequenos grupos, com um peso forte da localização geográfica, nem por isso exclui colaborações pontuais com investigadores de outras localizações geográficas, colaborações essas que têm normalmente na origem o cruzamento de percursos em instituições. Para o caso português, observa-se uma clara concentração em Lisboa dos autores inquiridos, para o brasileiro, uma certa dispersão geográfica, embora São Paulo seja o pólo dominante, com um conjunto de investigadores mais coesos que os demais.

A estrutura da rede e a identificação dos atores e grupos chave permitiram-nos compreender algo sobre a lentidão do processo de difusão da ARS. Sendo uma rede esparsa e muito descentralizada, o processo de difusão é mais lento. Para além disto, verificamos que não existem investigadores com um papel de destaque na difusão da ARS e que se possam considerar propriamente líderes do seu desenvolvimento. Nestas fases de desenvolvimento são os atores com intermediação alta que têm um papel preponderante na difusão e, como vimos, os níveis de intermediação nesta rede são muitíssimo baixos.

Vimos ainda que na fase de desenvolvimento de uma área científica os artigos de revistas são muito importantes para recrutar novos investigadores para o campo, mas os seus autores são normalmente periféricos. Estes são capazes de adotar a inovação mas depois não têm capacidade de influência, através de relações fortes, para a difundir. Efetivamente um dos artigos mais citados que integram a nossa base de artigos com aplicação de ARS é de uma autora que foi inquirida e se revela periférica nas diferentes redes aqui apresentadas, à exceção da rede de coautoria. Este é outro dado que nos ajuda a explicar a lenta difusão da inovação da ARS no mundo lusófono.

No que se refere ao atraso da introdução da ARS no mundo lusófono este poderá ser explicado em parte pelos baixos níveis de internacionalização dos analistas de redes lusófonos. Um número muito reduzido de investigadores lusófonos tem 
colaboradores ou coautores de outros países (recordamos que em média cada investigador lusófono tem 0,5 conselheiros não lusófonos). Este dado, em especial pensando no facto de que estamos a falar de uma área em fase de desenvolvimento, e sobre a qual cada investigador terá individualmente muitas dúvidas, é revelador da dificuldade de progressão nesta área do saber.

O atraso da introdução da ARS tem ainda a ver com o seu grau de complexidade e o grau em que diverge do status quo. A complexidade da ARS, no sentido em que exige um background matemático e estatístico que normalmente é pouco desenvolvido nos cursos de ciências sociais, mas também o facto de divergir dos métodos estatísticos ensinados nesses mesmos cursos, aumentam os custos da adoção e por isso atrasam a sua difusão. Dados do nosso inquérito, por exemplo quando revelam o número de investigadores que souberam da ARS através de bibliografia (e não através de outras pessoas), e a alta percentagem dos que utilizaram ARS só após o doutoramento, revelam os altos níveis do que poderíamos chamar autodidatismo.

Não deixa de nos causar alguma perplexidade que apesar da globalização, que se traduz numa grande mobilidade das pessoas e no recurso às tecnologias de comunicação e informação, a ARS nos países lusófonos, tenha sido introduzida tão tardiamente e se esteja a desenvolver tão lentamente. Com efeito, já bem entrados no séc. XXI se nota a sua expansão. Quais os reais obstáculos ao uso da ARS quando o conceito de "redes " é tão popular? Com base nos nossos dados não poderemos responder de forma definitiva a esta questão. O ainda reduzido número de cursos formais e oferecidos regularmente nesta área é, pensamos nós, um dos fatores que inibem a adoção da ARS como perspetiva teórico-metodológica.

Ao mesmo tempo, podemos dizer que este padrão de desenvolvimento da ARS nos países lusófonos não é diferente do padrão de desenvolvimento das ciências sociais em países periféricos. Segundo o World Social Science Report (UNESCO,2010) as disparidades na capacidade de investigação e a fragmentação do conhecimento caracterizam ainda o desenvolvimento científico a nível global.

\section{Bibliografía}

Allen, T. (1977), Managing the Flow of Technology, Cambridge, MA-MIT Press.

Almeida, P. e Kogut, B. (1999), "Localization of knowledge and the mobility of engineers in regional networks", Management Science, 45 (7), pp.905-917.

Becker, M. (1970), "Sociometric location and innovativeness: reformulation and extension of the diffusion model", American Sociological Review, 35, pp. 267-282. 
Borgatti, S.P. (2002), NetDraw: Graph Visualization Software, Harvard, Analytic Technologies.

Borgatti, S.P., Everett, M.G., Freeman, L.C. (2002), Ucinet for Windows: Software for Social Network Analysis, Harvard, MA - Analytic Technologies.

Bourdieu, Pierre (1989), O Poder Simbólico, Lisboa, Dífel.

Cantner, U. e Graf, H. (2006), "The network of innovators in Jena: An application of social network analysis", Research Policy, 35, pp.463-480.

Castells, M. (2000), "Materials for an exploratory theory of the netwok society", British Journal of Sociology, 51 (1), january/march.

Coleman, J.S., Katz, E., Menzel, H. (1966), Medical Innovation, New York, Bobs Merrill.

Crane, D. (1971), "Transnational networks in basic science", International Organization, 25, June, pp.585-601.

Cross, R. e Parker, A., Borgatti, D. (2002), "A bird's eye view: using Social Network Analysis to improve knowledge creation and sharing", IBM Institute for Knowledge Based Organisations, in Internet: http://www.gslis.utexas.edu/ i385q/spring2005/readings/Cross_2002_using_social _network.pdf (acedido a 24.03.2012).

Crozier, M. e Friedberg, E. (1977), L'Acteur et le Système, Paris, Éditions du Seuil.

Degenne, A. e Forse, M.(1999), Introducing Social Networks, London, Sage.

Everett, M. e Borgatti, S. (1998), "Analyzing clique overlap", Connections, 21(1), pp.49-61.

Festinger, L., Schachter, S., Back, K. (1950), Social Pressures in Informal Groups: a Study of Human Factors in Housing, California, Stanford University Press.

Freeman, L. (1979), "Centrality in social networks conceptual clarification", Social Networks, 1, pp.215-239.

Freeman, L. (2004), The Development of Social Network Analysis: A Study in the Sociology of Science, Vancouver, Empirical Press.

Gingras, Y. (2002), "Les formes spécifiques de l'internationalité du champ scientifique", Actes de la Recherche en Sciences Sociales, 141(42), pp. 31-45.

Gingras, Y. e Heilbron, J. (2009), "L'internationalisation de la recherche en sciences sociales et humaines en Europe (1980-2006)», in G. Sapiro (ed.), L'Espace 
Intellectuel en Europe, $X I X-X X e$ siècles [The Intellectual Sphere in Europe, XIXXXth Centuries], Paris,La Découverte.

Graeml, A. R., Macada, M. A., Rossoni, L. (2010), "Redes sociais e intelectuais em administração da informação: uma análise cientométrica do período 1997-2006", Informação e Sociedade, 20(1), jan./abr., p.95-110.

Hanneman, R., Riddle, M. (2005) Introduction to social network methods. Riverside:University of California http://faculty.ucr.edu/ hanneman/nettext/ (acedido a 24.03.2012).

Huisman, M. (2009), "Imputation of missing network data: some simple procedures", in

Internet: http://www.cmu.edu/joss/content/articles/volume10/huisman.pdf (acedido a 12.04.2012).

Hummon, N.P. e Carley, K. (1993), "Social networks as normal science", Social Networks, 15(1), pp.71-106.

Knoke, D. e Yang, S. (2008), Network Analysis, Beverly Hills-California, Sage.

Kossinets, G. (2006), "Effects of missing data in social networks", Social Networks, 28, pp.247-268.

Krackhardt, D. e Hanson, J.R. (1993), "Informal networks: the company behind the chart", Harvard Business Review, Julho-Agosto, pp.104-111

Kuhn, T.S. (1970), The Structure of Scientific Revolutions, Chicago, University of Chigago press (primeira edição de 1962).

Lazega, E. (2001), The Collegial Phenomenon, Oxford, Oxford University Press.

Marin, A. e Wellman, B. (2011), "Social network analysis: an introduction", in John Scott e Peter Carrington (eds.), The Sage Handbook of Social Network Analysis, London, Sage, pp.11-25.

Martins, D (2011), "A emergência da análise de redes sociais como campo de pesquisa: perspetiva da análise da produção científica em português e espanhol a partir do Google académico", Alexandria: Revista de Ciencias de la Informacion, 8, enero-deciembre, pp 17-29.

McPherson, M., Smith-Lovin, L., Cook, J.M. (2001), "Birds of a feather: homophily in social networks", Annual Review of Sociology, vol.27, pp.415-444

Menzel, H. (1960), "Innovation, integration and marginality: a survey of physicians", American Sociological Review, 25, pp.704-713. 
Miceli, Sergio (1987), "Condicionantes do desenvolvimento das ciências sociais no Brasil (1930-1964)", Revista Brasileira de Ciências Sociais, 2(5), pp. 5-26.

Michaelson, A.G. (1993), "Development of a scientific specialties diffusion through social relations: the case of role analysis", Social Network, 15, pp. 217-236.

Molina, J.L., Teves, L., Maya Jariego, I. (2004), "El analisis de redes en Iberoamérica: una agenda de investigación", REDES- Revista Hispana para el Analisis de Redes Sociales, 6, Jun/Jul.

Moody, J. (2004), "The structure of a social science collaboration network: disciplinary cohesion from 1963 to 1999", American Sociological Review, 69, pp. 213-238.

Otte, E. e Rousseau, R. (2002), "Social network analysis: a powerful strategy also for the information sciences", Journal of Information Science, 28(6), pp.441-453.

Piña- Stranger, A., (2011), Apprentissage collectif à l'échelle inter-organisationelle: le cas des entrepreneurs de biotechnologie, Tese de doutoramento, Université Paris-Dauphine.

Price, D. e J. de Solla (1986), Little Science, Big Science and Beyond, New York, Columbia university Press.

Rogers, E. M. (1995), Diffusion of Innovations, New York, The Free Press.

Rossoni, Luciano e Graeml, Alexandre (2009), "A influência da imersão institucional e regional na cooperação entre pesquisadores no Brasil", REDES-Revista Hispana para el Análisis de Redes Sociales, 16(9), pp.228-249.

Scott, J.(2000), Social Network Analysis: A Handbook, London, Sage.

Silva, Tânia Elias M. (2007), "Trajetórias da sociologia brasileira: considerações históricas", Cronos, 8(2), pp.429-449.

Small, H. G. e Griffith, B. C. (1974), "The structure of scientific literatures (I) Identifying and graphing specialties", Science Studies, 4(1), pp.17-40.

Stork, D. e Richards, W. (1992), "Nonrespondents in communication network studies", Group \& Organization Management, 17(2), pp.193-209.

UNESCO (2010), World Social Science Report: Knowledge Divides, UNESCO Publishing, in Internet: http://www.unesco.org/new/en/social-and-humansciences/resources/reports/world-social-science-report/ (acedido a 12.04.2012). Valente, T.W. (1995), Network Models of the Diffusion of Innovations, New Jersey, 
Hampton Press Inc.

Van Meter, K.(2005), "The development of social network analysis in the French speaking world", Social Networks, 27, pp. 275-282.

Wagner, C.S. e Leydersdorff, L. (2006), "Measuring the globalization of knowledge networks", Paper presented at "Blue Sky II 2006": What Indicators for Science, Technology and Innovation Policies in the 21st Century, Paris, OECD.

Wasserman, S. e Faust, K. (1994), Social Network Analysis: Methods and Applications, Cambridge, Cambridge University Press.

Wellman, B. (1988), "Structural analysis: from method and metaphor to theory and substance", in Barry Wellman e S.D. Berkowitz, Social Structures: A Network Approach, Cambridge, Cambridge University Press, pp 19- 61.

Wellman, B. e Haythornthwaite, C., (eds) (2002), The Internet in Everyday Life, Malden, Blackwell Publishing.

Ziegler, Rolf (2010)"Deustchsprachige Netzwerkforschung", in: Stegbauer, Christian e Roger Häussiling, (hrsg.). Handbuch Ntezwerkforschung,. Wiesbaden, VS Verlag, pp. 39-56. 


\section{Anexos.}

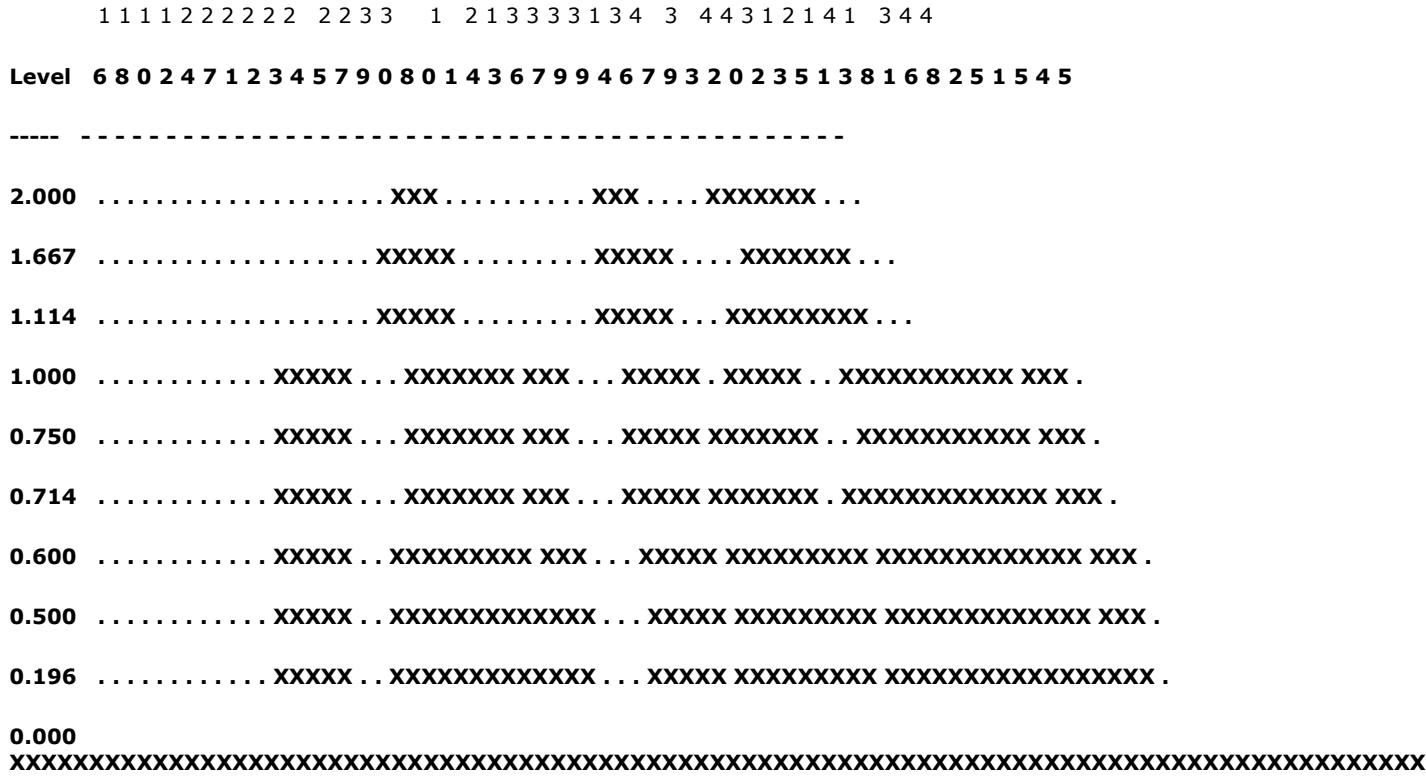

Tabela A. Clusters hierárquicos da sobreposição dos n-clans da rede de colaboração

$1122222222333213331344 \quad 11213331114444$

Level 250423456790803517667932013426799418885112345

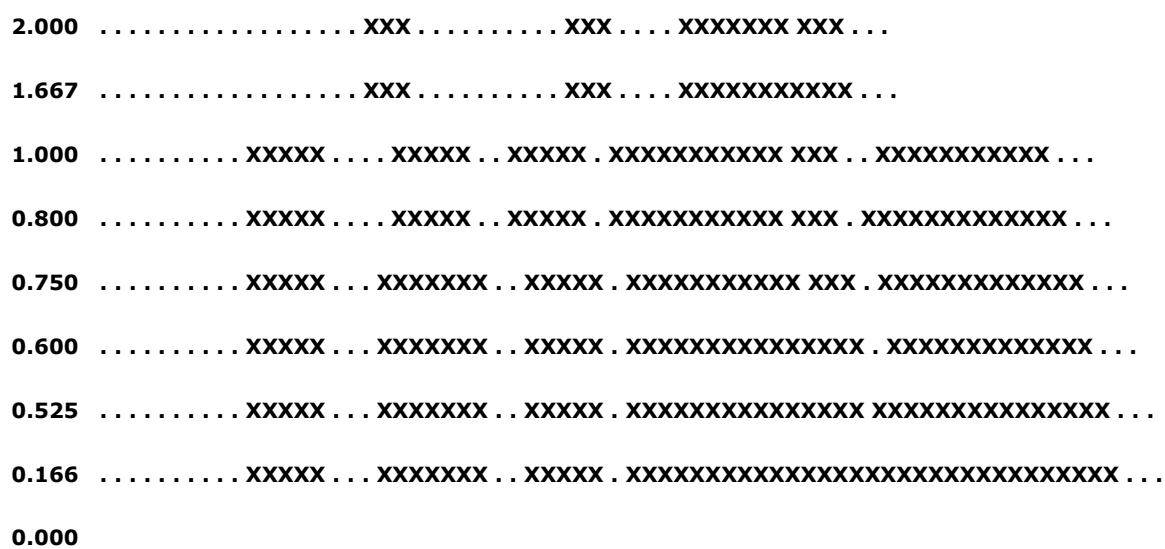

Tabela B. Clusters hierárquicos da sobreposição dos n-clans da rede de colaboração 
111111122222222223333333134311434444

Level 346789012467901234567890145679320858122315345

---- - - - - - - - - - - - - - - - - - - - - - - - - - - - - - - - - -

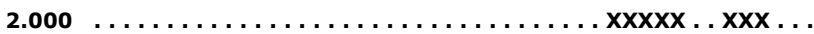

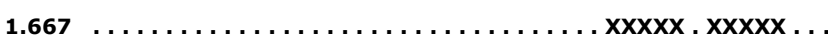

$1.000 \ldots \ldots \ldots \ldots \ldots \ldots \ldots \ldots \ldots \ldots \ldots \ldots \ldots x \operatorname{xxxx}, \operatorname{xxxxxxx}, \operatorname{xxxxx} \ldots$

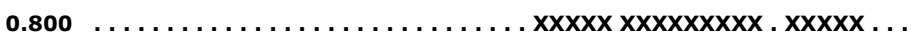

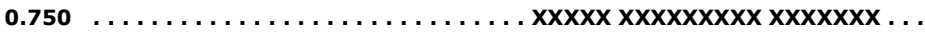

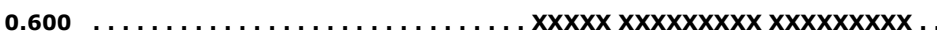

0.000

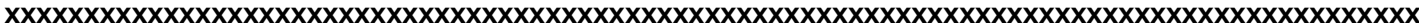

Tabela C. Clusters hierárquicos da sobreposição dos n-clans da rede de coautoria

\footnotetext{
$122222223211333134344 \quad 112133132411344$

Level 423457908010766793202351334267994118886251545

-1-- - -

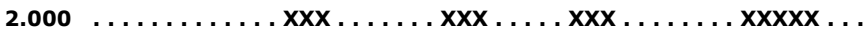

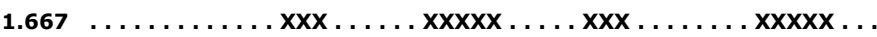

$1.267 \ldots \ldots \ldots \ldots x \operatorname{xxx} \ldots \ldots \operatorname{xxxxx} \ldots \ldots \operatorname{xxx} \ldots \ldots \operatorname{xxxxxxx\ldots }$

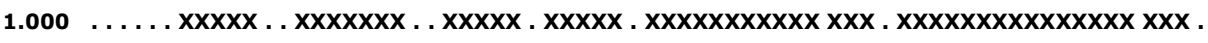

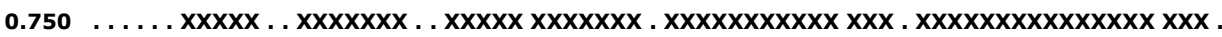

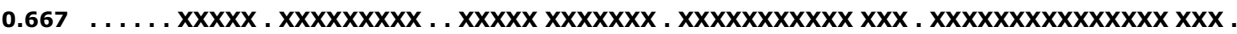

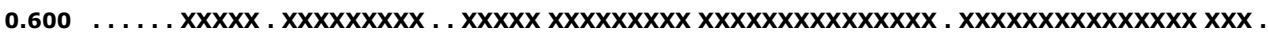

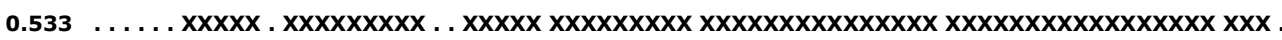

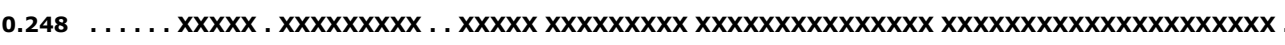

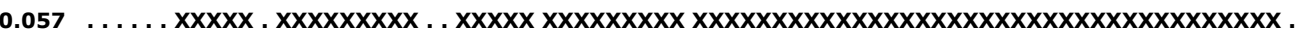

0.000

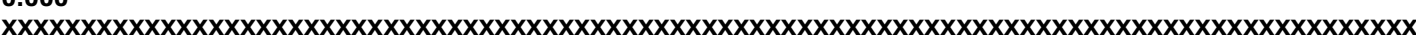

Tabela D. Clusters hierárquicos da sobreposição dos n-clans da rede multiplexa
} 